\title{
Clasificaciones climáticas aplicadas a Galicia: revisión desde una perspectiva biogeográfica
}

\author{
Recibido: 16 Xuño 2007 / Aceptado: 15 Outubro 2007 \\ (C) IBADER- Universidade de Santiago de Compostela 2007
}

Resumen En este trabajo se revisan los principales métodos de clasificación climática que han sido aplicados al territorio gallego, haciendo especial énfasis en aquellos orientados a explicar la relación entre parámetros climáticos y la distribución de los vegetales sobre la superficie terrestre (bioclimatología). Igualmente, se presentan por primera vez expresiones cartográficas de detalle (macrobioclimas, bioclimas, termotipos y ombrotipos) resultantes de la aplicación de la "Clasificación Bioclimática Mundial" de S. Rivas-Martínez a una base de 209 estaciones meteorológicas de Galicia y territorios próximos. Según esta clasificación bioclimática, la mayor parte del territorio de Galicia se encuentra dentro del macrobioclima templado, perteneciendo una proporción elevada del mismo a su variante submediterránea, mientras que solamente el tramo final de la cuenca del Río Sil y sus principales afluentes (Bibei, Xares, Lor) pertenecen al macrobioclima mediterráneo-pluviestacional. En cuanto al grado de continentalidad, se puede considerar que la mayor parte de Galicia presenta un clima poco contrastado (bioclimas hiperoceánicos y semioceánicos), debido al efecto modulador del mar. De esta tendencia se aleja únicamente el extremo SE que se incluye en el bioclima semicontinental. Los termotipos presentes en las áreas templadas son termotemplado, mesotemplado, supratemplado, orotemplado y criorotemplado, este último restringido a las cumbres más elevadas del macizo de Trevinca-Sanabria; dentro de las áreas mediterráneas se reconoce exclusivamente el termotipo mesomediterráneo. Los ombrotipos representados comprenden desde el subhúmedo inferior al ultrahiperhúmedo, siendo dominantes los de tipo húmedo (inferior y superior). Por último, se

Manuel A. Rodríguez Guitián

Depto. de Produción Vexetal. EPS. USC.

Campus Universitario S/N. Lugo (Galicia).

e-mail: fageta@lugo.usc.es

Pablo Ramil-Rego

Laboratorio de Botánica \& Bioxeografia. USC. IBADER

Campus Universitario S/N. Lugo (Galicia). discuten algunas cuestiones relativas a las limitaciones derivadas de la red de estaciones meteorológicas empleada así como la necesidad de su mejora para cubrir las crecientes demandas de información relativas al calentamiento global y su posible influencia en los hábitats terrestres, especialmente en las áreas de montaña.

Palabras clave Bioclimatología, clasificaciones, macrobioclimas, bioclimas, termotipos, ombrotipos.

Abstract The main methods of climatic classification that have been applied to the Galician territory are reviewed in this paper, stressing those aimed to explain the relationships between climatic parameters and the distribution of plants on land (bioclimatology). This the first time that detailed maps (macrobioclimates, bioclimates, termotypes and ombrotypes) were drawn from the results of the application of the S. Rivas' "World Bioclimatic Classification" to the data of 209 weather stations from Galicia and neighbouring territories. Our results show that the majority of the territory belongs to the temperate macrobioclimate, mostly to its submediterranean variant. Only the last stretch of the Sil river watershed and their main affluents (Bibei, Xares, Lor) belong to the mediterranean-pluvistational macrobioclimate. With regard to the continentality of the climate, most of the territory has low seasonal contrasts (hyperoceanic and semioceanic bioclimates) due to the buffering effect of the sea. Only the extreme SE area belongs to the semicontinental bioclimate. The termotypes found in the area were termotemperate, mesotemperate, supratemperate, orotemperate and (infered) criorotemperate, this last termotype being only present in the highest summits of the Trevinca-Sanabria range. In the mediterranean areas, only the mesomediterranean termotype was found. The ombrotypes found ranged from the lower subhumid to the ultrahyperhumid ombrotypes, being dominants the humid types (lower and upper). Finally, some issues are discussed which relate to the limitations caused by the weather station network employed and to the need of improving it to give a response to the growing needs of information related to global warming and its influence on terrestrial habitats, specially in mountainous areas.

Key words Bioclimatology, clasifications, macrobioclimates, bioclimates, termotypes, ombrotypes. 


\section{Introducción}

La importancia que el clima tiene a escala mundial sobre las características estructurales y florísticas de la cubierta vegetal es conocida desde hace más de 200 años. El estudio de las relaciones que se establecen entre los elementos del clima y la distribución de los seres vivos corre a cargo de la bioclimatología, ciencia mixta emanada de la climatología y la geobotánica que algunos autores encuadran dentro de la ecología. Ya desde sus inicios, esta disciplina se ha abordado el desarrollo de metodologías específicas encaminadas a determinar la relación existente entre la distribución de los seres vivos y determinados parámetros climáticos, en particular los rangos de temperaturas y precipitaciones anuales. Como resultado, se han propuesto un gran número de índices matemáticos y clasificaciones bioclimáticas, algunas de las cuales han tenido una gran acogida entre los estudiosos de diversas disciplinas científicas.

Köppen (1918), fue el primero en abordar una clasificación de los climas de la Tierra teniendo en cuenta precipitación y temperatura pero fijando los límites de cada tipo climático en función de cesuras en la distribución de la vegetación. Reconoció cinco zonas bioclimáticas en el mundo: tropical, subtropical, templada, fría y polar. Con posterioridad, diversos autores han tratado de obtener expresiones gráficas, resultado de cálculos matemáticos, en las que se sintetizaran los principales parámetros del clima que afectan a la constitución de la cubierta vegetal. Entre los más destacados quizá puedan citarse a Thornthwaite (1931), Emberger (1939), Gaussen (1954), Daget (1977), etc. Walter (1976), acuñó el concepto de "bioma", para referirse a grandes unidades ecológicas que incluyen tanto al ambiente como a los componentes bióticos. Además reconoció en la biósfera nueve biomas zonales o "zonobiomas" (ecuatorial, tropical, subtropical árido, mediterráneo, templado cálido, templado, templado árido, boreal y ártico), cuyo mayor determinante era el clima. También admitió, dentro de los zonobiomas, la necesidad de establecer subdivisiones en función, fundamentalmente, de la cuantía y/o efectividad de las precipitaciones.

Con unos objetivos claramente geobotánicos (=biogeográficos), Rivas-Martínez ha ido desarrollando a lo largo de los últimos 30 años una clasificación bioclimática propia aplicada inicialmente a los territorios del SW europeo (cf. 1979, 1983, 1987) que, con el paso del tiempo, se ha ido modificando para adaptarla a la totalidad del globo terrestre (cf. Rivas-Martínez \& Loidi 1999, Rivas-Martínez et al. 2002, Rivas-Martínez 2007). Bajo este enfoque, el citado autor reconoce cinco grandes áreas climáticas en el mundo (macrobioclimas) que son, desde el ecuador hacia los polos: tropical, mediterráneo, templado, boreal y polar. Inicialmente, esta clasificación estaba fundamentada en la obtención de una serie de índices bioclimáticos ("It", "Io" e "Im") a través de los que se determinaba el piso bioclimático, el ombrotipo y el grado de mediterraneidad de una estación dada mediante sencillos cálculos matemáticos en los que se combinaban, según los casos, valores de temperaturas, precipitaciones y ETP; en la actualidad, para suplir la escasez o irregularidad de las secuencias de datos climatológicos de una parte importante de las estaciones disponibles a nivel mundial, Rivas-Martínez utiliza principalmente los índices denominados "índice de termicidad compensado (Itc), "índice de continentalidad" (Ic), "índice ombrotérmico anual" (lo) e "índices estivales compensables" ( $\operatorname{los}_{2}, \operatorname{los}_{3}, y \operatorname{los}_{4}$ ), cuyo cálculo únicamente necesita de valores de temperatura y precipitaciones a nivel mensual.

\section{Clasificaciones climáticas aplicadas al territorio gallego}

Diversos autores han aplicado al territorio gallego clasificaciones climáticas a partir de las que se han obtenido diferentes expresiones cartógraficas en las que se trata de reflejar la relación entre parámetros del clima y aspectos de la cubierta vegetal natural o más o menos influenciada por la actividad humana, asi como diversas cuestiones relacionadas directamente con esta última, tales como la distribución de tipos de cultivos y rotaciones agrícolas, tipologías de aprovechamiento del medio rural, grado de confort o habitabilidad para el ser humano, etc. (cf. DíazFierros Viqueira 1971; Carballeira et al. 1983; de Uña Álvarez 2001). En el presente trabajo haremos mención de aquellas que, por su carácter más reciente y por su orientación, han supuesto algún avance o mejora sustancial en la comprensión del fenómeno de la distribución de las especies vegetales y las comunidades que constituyen dentro del territorio de Galicia.

Quizás el punto de partida de las clasificaciones climáticas orientadas a la comprensión de la cubierta vegetal lo constituye, la hoy en día clásica y enormemente difundida, contraposición entre la "Iberia húmeda" e "Iberia seca", introducida por el geógrafo francés Jean Brunhes (1902) tomando como referencia la isohieta de $600 \mathrm{~mm}$. Esta dicotomía fue mantenida, con algunos matices, por geógrafos y fisiógrafos, como Hernández Pacheco, Dantín Cereceda o Lautensach, entre otros, hasta bien entrada la segunda mitad del siglo XX (Figuras 1 y 2 ).

Otros autores, sin embargo, han planteado clasificaciones climáticas para el ámbito ibérico en las que se tiene en cuenta, no sólo la cantidad total de precipitación recogida, sinó su reparto a lo largo del año, con el ánimo de delimitar geográficamente el carácter fuertemente estacional de las áreas típicamente mediterráneas frente a las de mayor influencia oceánica, en las que existe un aporte de lluvias mucho más regular, así como el grado de oceaneidad/continentalidad de los diversos sectores peninsulares (cf. Masachs Alavedra 1952) (Figura 3). Así, en algunos casos se llegan a diferenciar tres grandes unidades, oceánica o atlántica, mediterránea y continental, que llevan asociadas connotaciones relacionadas con los tipos de paisaje y cubierta vegetal que las caracterizan, de manera que se han utilizado, en muchos casos de manera indirecta, para establecer relaciones entre estos elementos del clima y tipologías particulares del paisaje que se repiten a lo largo de dichas unidades geo-climáticas, originando rasgos diferenciadores específicos (cf. Font Quer 1952). 
En otros casos, se han integrado los tipos de tiempo dominantes y el régimen pluviométrico junto a índices hídricos y de continentalidad para establecer una tipología de climas regionales a escala ibérica. Así, Font Tullot (2000) ha mantenido la clásica dicotomía "Iberia húmeda/lberia seca", aunque en este caso identificada a través de los términos "Zona parda" y "Zona verde", pero introduciendo una amplia gama de subdivisiones asociadas con características climáticas particulares (Figura 4). En esta clasificación se mantiene el criterio, ya planteado en propuestas previas (cf. Masachs Alavedra 1954) de que las áreas interiores de la Peninsula muestran un carácter más

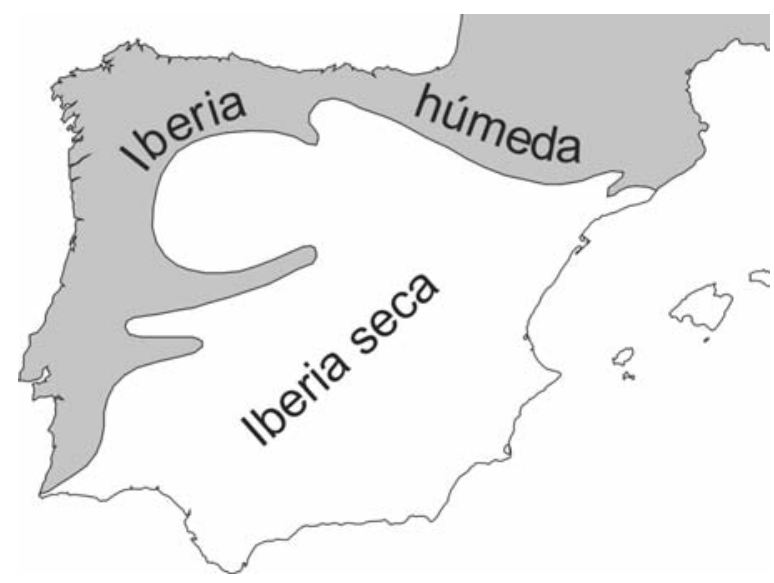

Figura 1.- Delimitación aproximada de la "Iberia húmeda" e "Iberia seca" según Dantín Cereceda (1913)

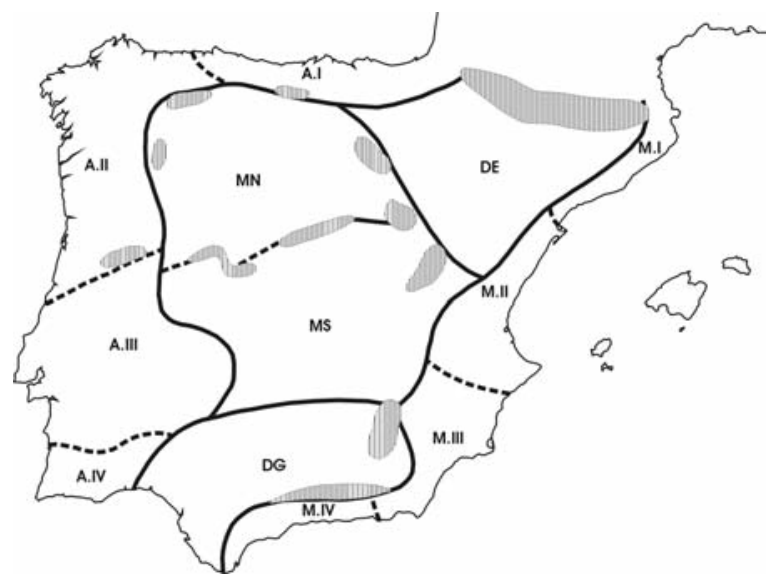

Figura 3.- Tipos climáticos presentes en la Península lbérica según Masachs Alavedra (1954). A: I, II, III y IV: climas costeros de la región atlántica, M: I, II, III y IV: climas costeros de la región mediterránea; MN y MS: climas interiores de la Meseta; DE y DG: climas interiores de las depresiones del Ebro y del Guadalquivir. En rayado: climas de montaña

En todas estas clasificaciones climáticas, Galicia figura de manera constante dentro de las áreas consideradas bajo climas de condiciones atlánticas, con una elevada pluviometría, si bien es preciso descatar que, en su o menos acusado de continentalidad y que las diferencia claramente de los territorios periféricos próximos al Océano Atlántico y los mares Cantábrico y Mediterráneo. Se define así una "región continental" que, desde una perspectiva geobotánica integradora, vendría a coincidir con el dominio que los estudios paleobotánicos atribuyen a bosques de carácter helio-xerófilo, principalmente pinares de $P$. pinaster y $P$. nigra, en las áreas meseteñas ibéricas, la mayor parte de los cuales han desaparecido debido a procesos deforestadores antrópicos en épocas históricas o prehistóricas recientes (cf. Ramil-Rego et al. 1998; Alcalde Olivares et al. 2004).

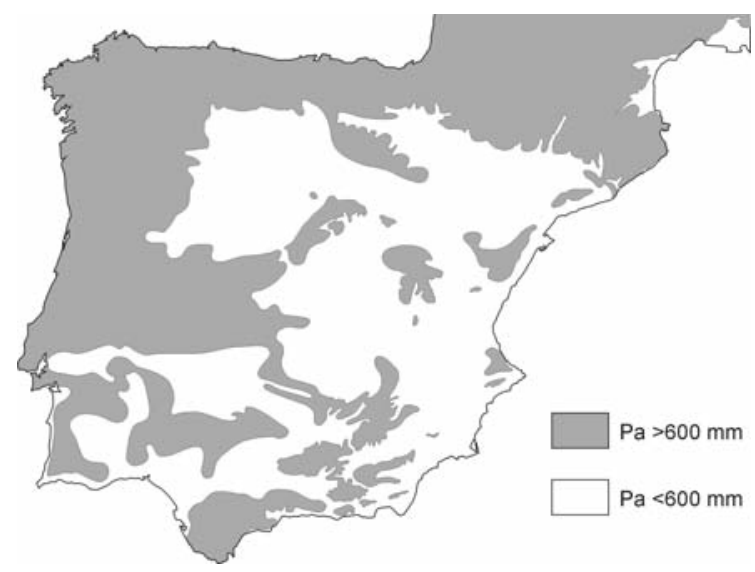

Figura 2.- Delimitación aproximada de la "Iberia siempre húmeda" e "Iberia de veranos secos" según Lautensach (1967). Pa: precipitación anual

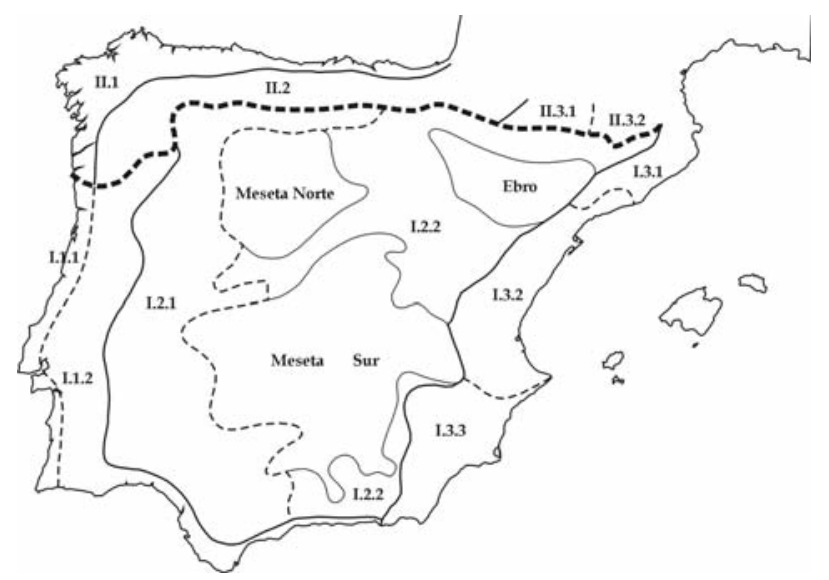

Figura 4.- Tipos climáticos presentes en la Península Ibérica según Font Tullot (2000). I: Zona Parda (mediterránea): I.1: región atlántica; I.1.1: subregión marítima; I.1.2: subregión submarítima; I.2: región continental; I.2.I: subregión continental atenuada; 1.2.2: subregión continental extremada; I.3: región mediterránea; I.3.1: subregión Norte; I.3.2: subregión Levantina; I.3.3: subregión sudeste. II: Zona Verde (clima europeo occidental); II.1. región marítima; II.2: región semimarítima; II.3: región pirenaica; II.3.1: subregión pirenaica central; II.3.2: subregión pirenaica oriental

inmediata proximidad se suele situar el límite con las áreas consideradas como de caracter mediterráneo.

Pasando al análisis de propuestas centradas de manera específica en el territorio gallego, Pérez Alberti publicó a 
principios de los años '80 en diversos trabajos $(1982,1983)$ una división del territorio gallego en "dominios climáticos", definidos por combinaciones de parámetros termométricos y pluviométricos que se resuelven en las siete unidades que se muestran en la Figura 5. Dicho autor establece la existencia de una serie de vínculos entre estas unidades y diversas características del medio (formas del relieve, cubierta vegetal, formas de aprovechamiento de los recursos) y del poblamiento humano que utiliza para realizar sus descripciones geográficas de Galicia. Destaca en esta propuesta, que se mantuvo en trabajos posteriores hasta bastantes años después (cf. Torres Luna et al. 1993), la consideración de gran parte de Galicia dentro de las unidades tipificadas como "oceánicas" y la de "oceánicomediterránea" para el tramo medio del Miño y la cuenca del Sil, mientas que el conjunto montañoso septentrional y la Dorsal Gallega se incluirían dentro de las llamadas "áreas de transición".

La publicación en 1983 de la obra "Bioclimatología de Galicia” por Carballeira et al. constituyó la culminación de una serie de trabajos previos sobre la caracterización climática de este territorio mediante la aplicación de técnicas estadísticas a las series de datos normalizadas de un total de 124 estaciones meteorológicas situadas en Galicia y en su inmediata periferia. En dicha obra, entre otras cuestiones, se aplican al caso gallego diversas clasificaciones climáticas, algunas de ellas adaptadas de forma específica a las peculiaridades de este espacio geográfico. Desde el punto de vista bioclimático, son destacables las cartografías elaboradas por estos autores como resultado de la aplicación de índices ombrotérmicos orientados a discriminar territorios de carácter atlántico y otros mediterráneos que presentan diferentes intensidades de sequía, como los otenidos a partir del cálculo de los cocientes pluviotérmicos de Emberger ("Q") o de Baudiere (" $\left.Q_{D}\right)$. Es especialmente llamativo en los resultados obtenidos por estos autores el hecho de que en la mayor parte de clasificaciones aplicadas al territorio gallego, una parte de las Rías Baixas y del interior de Ourense son considerados como de clima mediterráneo.

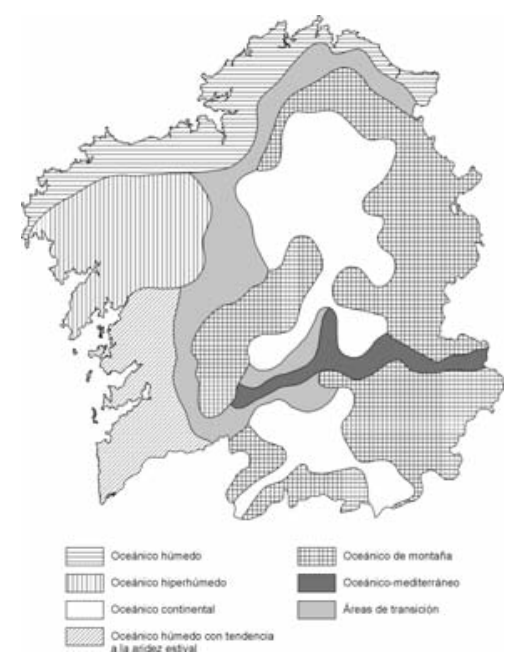

Figura 5.- Dominios climáticos de Galicia según Pérez Alberti (1982)
Otra aportación significativa de esta obra es la plasmación cartográfica, a una escala de detalle sensiblemente superior a la realizada inicialmente por su autor, de la tipología de "Subregiones fitoclimáticas" ideada por Allué Andrade en 1966 (Figura 6). En esta representación se observa una cierta diversidad de unidades fitoclimáticas, acorde con la variedad de situaciones climáticas que se habían determinado en estudios precedentes, estableciéndose el caracter atlántico de las áreas coruñesas, gran parte de la provincia de Pontevedra y el $\mathrm{N}$ de Lugo. Nuevamente, la aplicación de esta clasificación al caso gallego, incide en la existencia de una componente mediterránea en su clima que afectaría a las áreas bajas del Golfo Ártabro, las partes externas de las Rías Baixas, la cuenca baja del sistema Miño-Sil-Cabe y la Baixa Limia. Por último, la mayor parte de las áreas de montaña, tanto sublitorales como interiores, aparecen incluídas en la "Subregión Centroeuropea", mientras que las altas cumbres de Os Ancares, Queixa y Trevinca-Segundeira pertenecerían al dominio de la "Alta Montaña".

A principios de la década de los '90, Allué Andrade (1990) publicó, siguiendo una metodología totalmente diferente a la planteada para el caso de las subregiones fitoclimáticas y dada conocer un par de años antes (Allué Andrade 1988), el "Atlas Fitoclimático de España", en el que se aporta una cartografía a escala 1:1.000.000 de unidades descritas en esta obra. Para el caso de Galicia, la aplicación de esta nueva metodología conduce a considerar la mayor parte del territorio dentro de las tipologías "nemorales", restringiéndose las áreas mediterráneas a una estrecha banda ceñida al tramo gallego del Río Sil y su prolongación a través del Miño, entre Os Peares y la cola de la Presa de Velle (Ourense). Frente a la propuesta planteada en el caso de las subregiones bioclimáticas, la mayor parte de la provincia de Ourense y el $\mathrm{S}$ de la de Lugo pasan, en esta ocasión, a interpretarse como zonas de carácter transicional (tipologías nemoromediterráneas) mientras que los sectores de cumbres de los principales sistemas montañosos del oriente gallego (A Fonsagrada, Ancares-Courel, Queixa, Trevinca-Segundeira) se incluyen en fitoclimas de tendencia ártico-boreal ("oroborealoide" y "oroarticoide")(Figura 7).

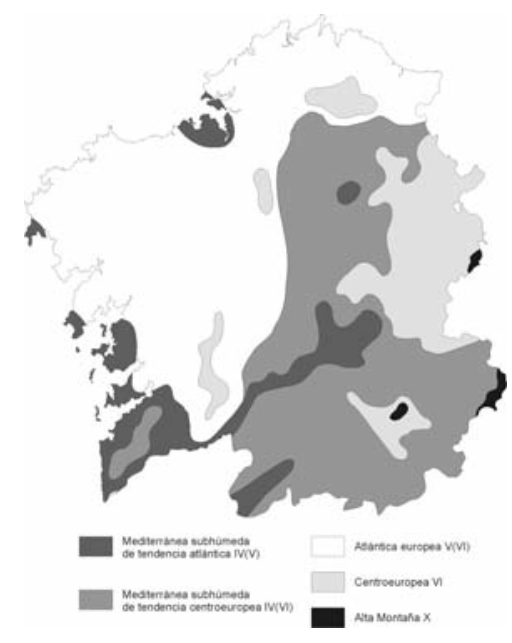

Figura 6.- Regiones fitoclimáticas de Allué Andrade (1966). Modificado de Carballeira et al. (1983) 


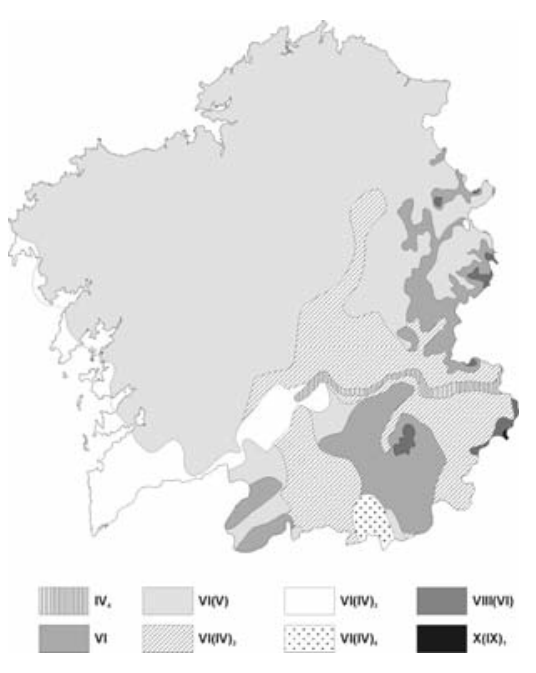

Figura 7.- Tipos fitoclimáticos presentes en Galicia según la clasificación de Allué Andrade (1990)

En gran medida, la desigual densidad y reparto de estaciones meteorológicas que han servido de base para esta clasificación explica el peculiar reparto geográfico de alguno de los tipos fitoclimáticos comentados, que no tienen una correspondencia demasiado fiel con la configuración del relieve, en contra de lo esperable, como puede apreciarse en las discontinuidades y límites que presentan los tipos $\mathrm{VI}(\mathrm{IV})_{2}, \mathrm{VI}(\mathrm{V})$ o $\mathrm{VIII}(\mathrm{VI})$. La correspondencia establecida por este autor entre tipos fitoclimáticos y las características de la cubierta vegetal (atributos fitológicos) otorga a la mayor parte de Galicia el predominio potencial de las formaciones arboladas planocaducifolias, bien sean típicas o de carácter marcescente, mientras que en las áreas mediterráneas éste correspondería a los denominados "bosques ilicinos".

El empleo de una mayor cantidad de estaciones y el contraste de parámetros climáticos con la distribución de 55 especies vegetales leñosas permitió a Carballeira \& Retuerto (1990) una delimitación de tipos fitoclimáticos más detallada que en el caso anterior (Figura 8). En este caso se utilizaron como parámetros definitorios de los fitoclimas las limitaciones por frío, cuantificadas a través de los valores de las temperaturas medias de las mínimas del mes más frío $\left(\mathrm{MIN}_{\text {frio }}\right)$, y la duración e intensidad de la sequía (QE), determinado mediante el "cociente pluviotérmico de Baudiere". El resultado de las combinaciones establecidas por los autores de esta propuesta es la existencia dentro del territorio gallego de 12 tipos fitoclimáticos, de los que 5 serían mediterráneos y los restantes "lluviosos" o "muy lluviosos". Los tipos "mediterráneo húmedo" y "lluvioso húmedo" incluyen variantes termométricas que cubren desde situaciones "muy frías" hasta "templadas"; sin embargo solamente se contempla una variante de carácter "fresco" dentro del tipo "mediterráneo subhúmedo" y las "muy fría" a "fresca" dentro del fitoclima "muy lluvioso".

En la "Clasificación Biogeoclimática de España Peninsular y Baleares" (Elena Roselló 1997) se integran, junto a aspectos geológicos, litológicos y topográficos no

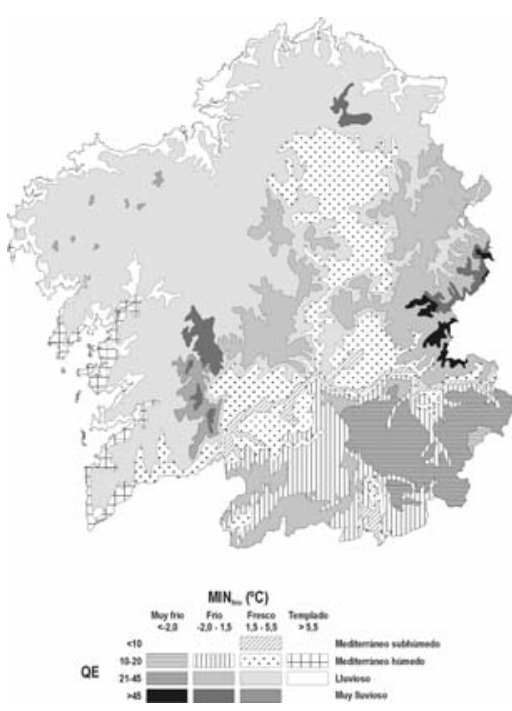

Figura 8.- Clasificación fitoclimática de Galicia. Adaptado de Retuerto \& Carballeira (1990)

considerados en las clasificaciones comentadas anteriormente, atributos de tipo climático y fitoclimático (clasificación de Allué Andrade 1990), lo que repercute en el elevado número de "clases territoriales" obtenidas. En función de la descripción de las unidades presentes en Galicia que aporta el autor comentado se obtiene la cartografía de fitoclimas que se muestra en la Figura 9. Como puede observarse, aunque la escala de detalle es sensiblemente superior en este trabajo, existen una gran coincidencia entre la distribución de tipos fitoclimáticos cartografiados en la propuesta por Allué Andrade (1990), por lo que son de aplicación los comentarios anteriormente realizados sobre aquella.

El examen de la cartografía de fitoclimas confeccionada por estos autores, mucho más detallada en la definición geográfica de las unidades que en propuestas precedentes, muestra el predominio de fitoclimas lluviosos en Galicia y la localización de las áreas mediterráneas, de manera redundante con otras propuestas ya comentadas, a lo largo del litoral de las Rías Baixas, la penetración Miño-Sil a lo largo del interior de Galicia y dos pequeñas áreas en la parte meridional: Baixa Limia y Val de Verín. No obstante, creemos que la denominación de "mediterráneo" aplicada a los tipos fitoclimáticos que caracterizan gran parte del interior de las provincias de Lugo y Ourense y de las Rías Baixas no se corresponden con la realidad florística y vegetacional de estos territorios, ya que en ellos son claramente predominantes en el paisaje forestal los bosques de Quercus robur, aunque si bien es cierto que con una proporción variable de $Q$. pyrenaica, y los matorrales dominados por leguminosas (Ulex europaeus, Cytisus striatus, C. scoparius) y ericáceas (Calluna vulgaris, Daboecia cantabrica, Erica arborea, Erica australis, E. cinerea), como es propio de toda la fachada atlántica del NW Ibérico. Con respecto al aspecto termoclimático de esta clasificación, las áreas de montaña se incluyen en las variantes frías o muy frías, mientras que los territorios próximos al litoral o interiores de media y baja altitud presentan fitoclimas frescos (dominantes) o templados. 


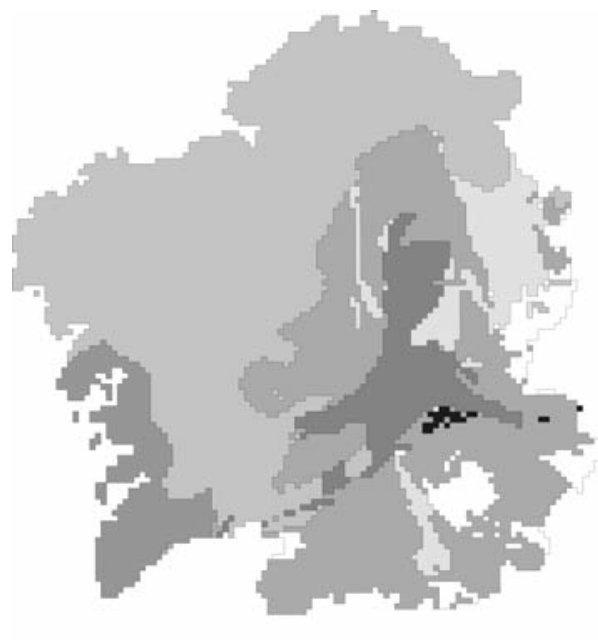

\begin{tabular}{|l|l|l|l|l|l|l|}
\hline 1 & 2 & 3 & 4 & 5 & 6 & 7 \\
\hline
\end{tabular}

Figura 9.- Representación gráfica de los fitoclimas asociados a las ecorregiones ("clases territoriales") presentes en Galicia según Elena Roselló (1997). 1: fitoclima $\mathrm{IV}_{4}$ (mediterráneo genuino); 2: fitoclima $\mathrm{VI}(\mathrm{IV})_{3}$ (nemoromediterráneo subnemoral); 3: fitoclima $\mathrm{VI}(\mathrm{IV})_{2}$ (mediterráneo subnemoral); 4: fitoclima $\mathrm{VI}(\mathrm{V})$ (nemoral genuino); $5: \quad$ fitoclima $\quad \mathrm{VI}(\mathrm{IV})_{4} \quad$ (nemoromediterráneo submediterráneo); 6: fitoclima VI (nemoral genuino) 7: fitoclima VIII(VI) (oroborealoide subnemoral)

A finales del pasado siglo, Martínez Cortízas \& Pérez Alberti (1999) publicaron una clasificación ombrotérmica de Galicia basada en la integración del reparto espacial de los valores de precipitación y temperatura medios anuales sobre un modelo digital del terreno, resultando la distribución de unidades ombrotérmicas que se muestra en la Figura 10. En esta propuesta destacan los bajos niveles pluviométricos que estos autores atribuyen a gran parte de la Galicia interior, especialmente el centro-sur de Lugo y la mitad occidental de la provincia de Ourense, que aparecen incluidos en los tipos climáticos "cálido seco" y "cálido muy seco". Esta calificación resulta especialmente llamativa en el caso de la cuenca baja del Río Miño (comarcas de O Carballiño, O Ribeiro, Terra de Celanova y Ourense), la Baixa Limia y el Valle de Verín que, según estos autores, formarian parte de la misma unidad (cálida y muy seca) que comprende la Ribeira Sacra y las partes bajas de la comarca de Valdeorras. La confrontación de la cubierta vegetal actual de estas áreas y la sectorización climática propuesta por estos autores muestra, sin embargo, la existencia de claras incongruencias, pues de ser su hipótesis cierta, cabría encontrar aguas abajo de la unión de los ríos Miño y Sil un paisaje dominado por vegetación de tipo mediterráneo (encinares, alcornocales con encina, jarales, tomillares, etc.), semejante al que caracteriza el Cañon del Sil y los valles de Quiroga y Valdeorras, cosa que, como es bien sabido, no ocurre.

En el mismo sentido habría que hablar con relación a los bajos niveles pluviométricos estimados para las montañas del macizo de Segundeira-Trevinca-Sanabria, incluidas casi en su totalidad dentro de las categorías "secas" y "subhúmedas" a pesar de que alcanzan niveles altitudinales iguales o sensiblemente superiores a las sierras vecinas del macizo de Manzaneda que, sin embargo, figuran dentro de

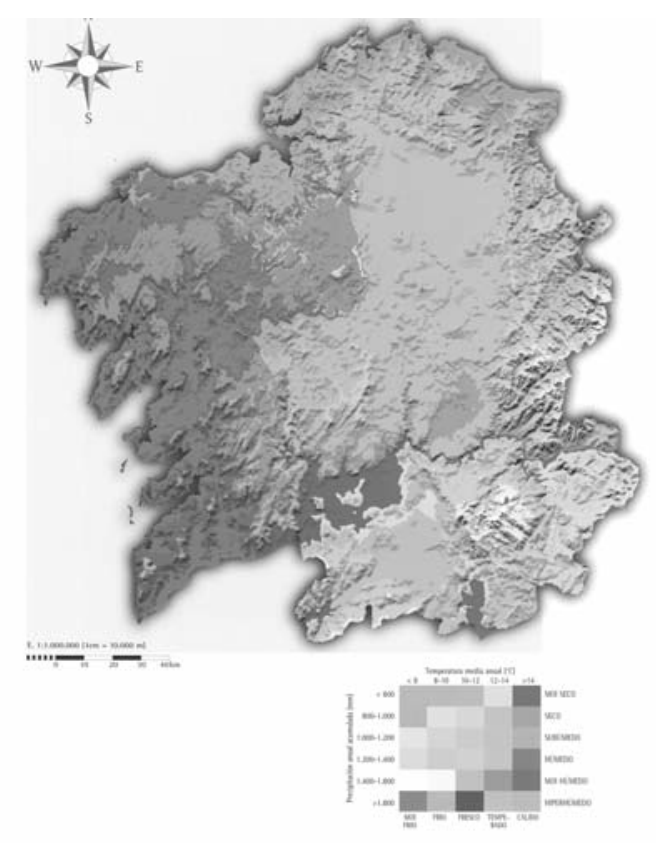

Figura 10.- Regímenes ombrotérmicos de Galicia según Martínez Cortizas \& Pérez Alberti (1999)

los tipos "muy húmedo" o "hiperhúmedo". En gran medida esta interpretación podría estar condicionada por el empleo de estaciones meteorológicas exclusivamente dentro del territorio gallego, dejando a un lado las más proximas situadas en territorios limítrofes, que, de haberse empleado, habrían contribuido a modular las interpretaciones obtenidas de esta otra manera. De hecho, si bien se desconocen los valores pluviométricos reales de las cumbres de las montañas comentadas y, aunque los valores registrados en las estaciones situadas a mayores altitudes dentro de este macizo (Embalse de Laguna Cárdena [1.600 $\mathrm{m}$ ]: $1682 \mathrm{~mm}$; Porto [1.200 m]: $1430 \mathrm{~mm}$ ) son inferiores a la obtenidas en altitudes similares dentro del Macizo de Manzaneda (Cabeza de Manzaneda [1.500 m]: $2.347 \mathrm{~mm}$; Cenza [1.500 m]: $1.900 \mathrm{~mm}$ ), la posición a sotavento de las citadas estaciones sanabresas permite suponer que en la vertiente gallega de este macizo (sierras Segundeira y Calva) se alcancen niveles de precipitación muy semejantes a los del Macizo Central ourensano. A idéntica conclusión llega Font Tullot (2000) en su trabajo sobre climatología de España y Portugal.

\section{Aplicación de la Clasificación Bioclimática Mundial (Rivas-Martínez 2007) al territorio gallego}

El conocimiento de las relaciones que existen entre los parámetros climáticos y la distribución de especies y comunidades vegetales se considera fundamental para valorar correctamente las particularidades biogeográficas de las diferentes áreas continentales. Dentro del ámbito ibérico, Rivas-Martínez ha realizado sucesivas propuestas metodológicas y adaptaciones de su clasificación 
bioclimática, cuya génesis conceptual se ha ido esbozando a lo largo de numerosos trabajos publicados entre los años '60 y '80 del siglo pasado, y se ha visto plasmada en el apartado de bioclimatología que acompaña a la "Memoria del Mapa de Series de Vegetación de España" (RivasMartínez 1987). A partir de este momento, dicha clasificación fué adaptada y aplicada sucesivamente al continente europeo (1996), América del Norte (RivasMartínez 1997; Rivas-Martínez et al. 1999) y, finalmente, la totalidad de las tierras emergidas (Rivas-Martínez \& Loidi 1999). A lo largo de las sucesivas modificaciones realizadas, Rivas-Martínez ha intentado dotar a su sistema de clasificación bioclimática del máximo grado de resolución posible y optimizar el carácter predictivo de los índices matemáticos propuestos con relación a la distibución de los grandes tipos de vegetación existentes en el Planeta. Consciente de la disparidad de situaciones que se pueden encontrar en lo relativo a la disponibilidad de datos climáticos fiables en los distintos territorios, el citado autor ha previsto diversos procedimientos matemáticos para establecer de manera indirecta una diagnosis bioclimática apropiada en los casos de mayores limitaciones.

Aunque desde inicios de los años '80 la mayor parte de los estudios sobre vegetación realizados en Galicia, como en multitud de los realizados en el resto de España, han utilizado la clasificación bioclimática de Rivas-Martínez (cf. Amigo 1984; Guitián Rivera 1984; Izco et al. 1985, Ortiz 1986; Izco 1987; Rodríguez-Oubiña 1987; Giménez de Azcárate 1993, etc.), no fué hasta la década de los '90 que se publicó la primera cartografía de pisos bioclimáticos de este territoro. Se trataba de un mapa a gran escala contenido en una publicación de Ortiz \& Rodríguez-Oubiña (1993) en el que se delimitaban a grosso modo los pisos bioclimáticos existentes en Galicia incorporando el concepto definido por Izco (1988) para el denominado "piso termocolino", que no estaba contemplado en las propuestas iniciales de Rivas-Martínez (cf. Rivas-Martínez 1979, 1987)(Figura 11).

Poco tiempo después, Amigo \& Romero (1994) publicaron una adaptación de la tipología bioclimática de RivasMartínez con la finalidad de precisar el límite entre los territorios eurosiberianos y mediterráneos en el $\mathrm{S}$ de la provincia de Lugo (comarcas de Terra de Lemos y Ribeira Sacra), mediante la modificación de las fórmulas propuestas el autor comentado. Dichos territorios habían sido considerados hasta esa fecha como de carácter mediterráneo; sin embargo el estudio detallado su cubierta vegetal (cf. Romero 1993) demostró su carácter atlántico, si bien es cierto que con una proporción elevada en algunas comunidades estudiadas de plantas frecuentes en las áreas mediterráneas, en sintonía con la existencia de una cierta sequía estival.

A la vista de lo recogido en multitud de trabajos de tipo biogeográfico y botánico publicados en las últimas décadas, la clasificación bioclimática ideada por Rivas-Martinez explica con un elevado grado de precisión la relación existente entre la expresión regional de diversos elementos del clima (rangos anuales de precipitaciones y temperaturas, grado de continentalidad, intensidad del período de sequía) y las características fisionómicas y

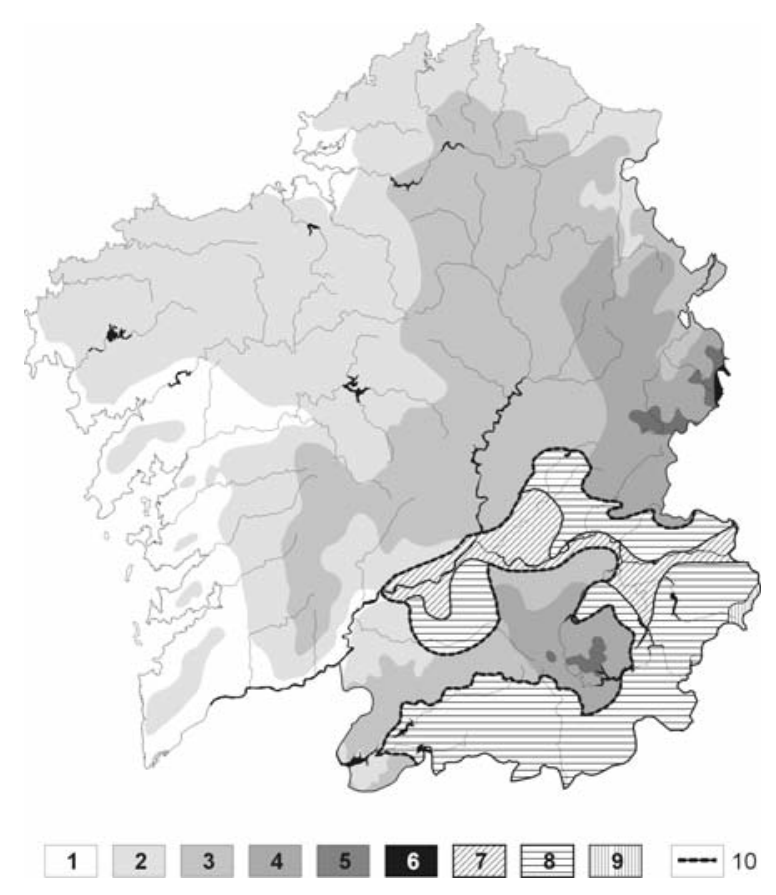

Figura 11.- Distribución de los pisos bioclimáticos en Galicia según Ortiz \& Rodríguez-Oubiña (1993). 1: termocolino; 2: eucolino; 3: colino superior; 4: montano inferior; 5: montano superior; 6: subalpino inferior; 7: mesomediterráneo; 8: supramediterráneo; 9: oromediterráneo; 10: límite eurosiberiano-mediterráneo

florísticas de la cubierta vegetal. A pesar de lo anteriormente expresado, y a diferencia de lo acontecido en áreas españolas próximas a Galicia (cf. Díaz González \& Fernández Prieto 1994; Penas Merino et al. 1995a, 1995b) o Portugal (Tormo Molina et al. 1992; Mesquita 2005), hasta el momento no se ha realizado ningún trabajo detallado de aplicación a la totalidad del territorio gallego de la citada clasificación bioclimática, constituyendo las figuras que ilustran la publicación de Ortiz \& Rodríguez-Oubiña (1993) sobre comunidades rupícolas el intento cartográfico de mayor detalle que se tiene hasta el momento (Figura 11). Recientemente, Rivas-Martínez et al. (2002) han publicado un mapa de síntesis de los macrobioclimas, bioclimas y termotipos presentes en España y Portugal que, particularizados para el caso de Galicia, se representan en las Figuras 12 y 13. Debido a la baja resolución de escala cartográfica empleada, la delimitación de unidades bioclimáticas en estos documentos es claramente imprecisa y no permite su aplicación directa en estudios de detalle que pudieran realzarse en los diversos territorios peninsulares e insulares cartografiados.

La aplicación de esta metodología al ámbito gallego es una cuestión que estimamos de interés, cuando menos, en los ámbitos científico-técnicos vinculados con el estudio, interpretación y conservación de la cubierta vegetal de nuestro país, así como en aspectos fundamentales relacionados con la planificación y gestión forestal. Es por ello que, como apartado final del presente trabajo, presentamos los mapas obtenidos al aplicar a una base de 


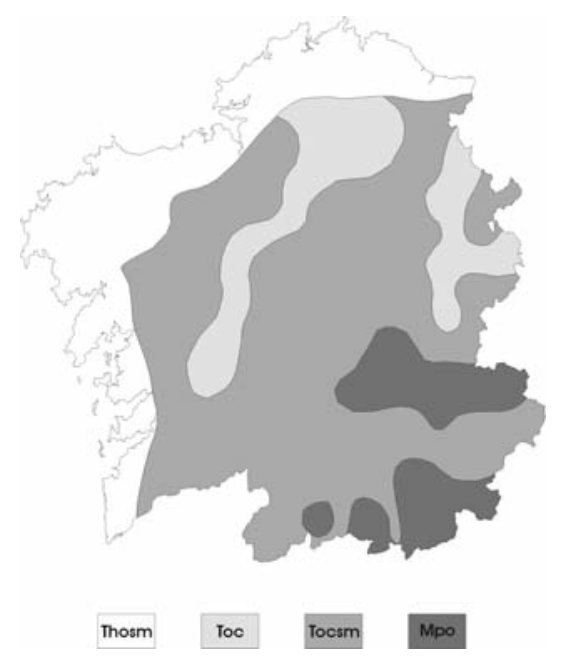

Figura 12.- Macrobioclimas y bioclimas presentes en Galicia según Rivas-Martínez et al. (2002). Thosm: templado (submediterráneo) hiperoceánico; Toc: templado oceánico; Tocsm: templado (submediterráneo) oceánico; Mpo: mediterráneo pluviestacional oceánico

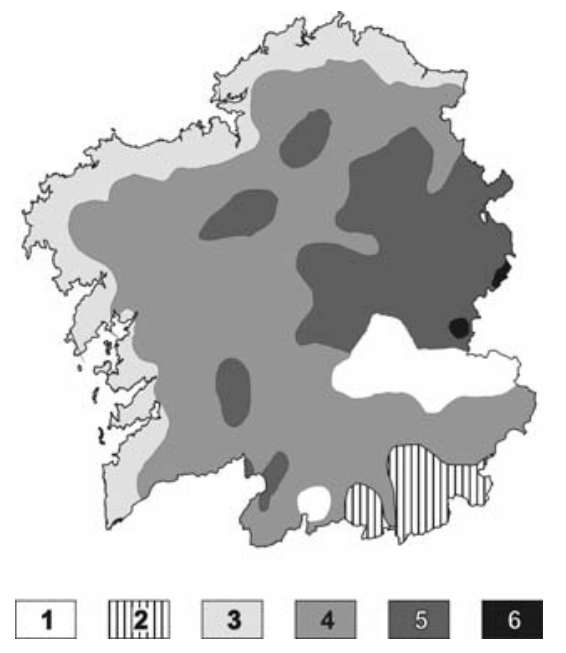

Figura 13.- Termotipos presentes en Galicia según Rivas-Martínez et al. (2002). 1: mesomediterráneo; 2: supramediterráneo; 3: termotemplado; 4: mesotemplado; 5: supratemplado; 6 : orotemplado

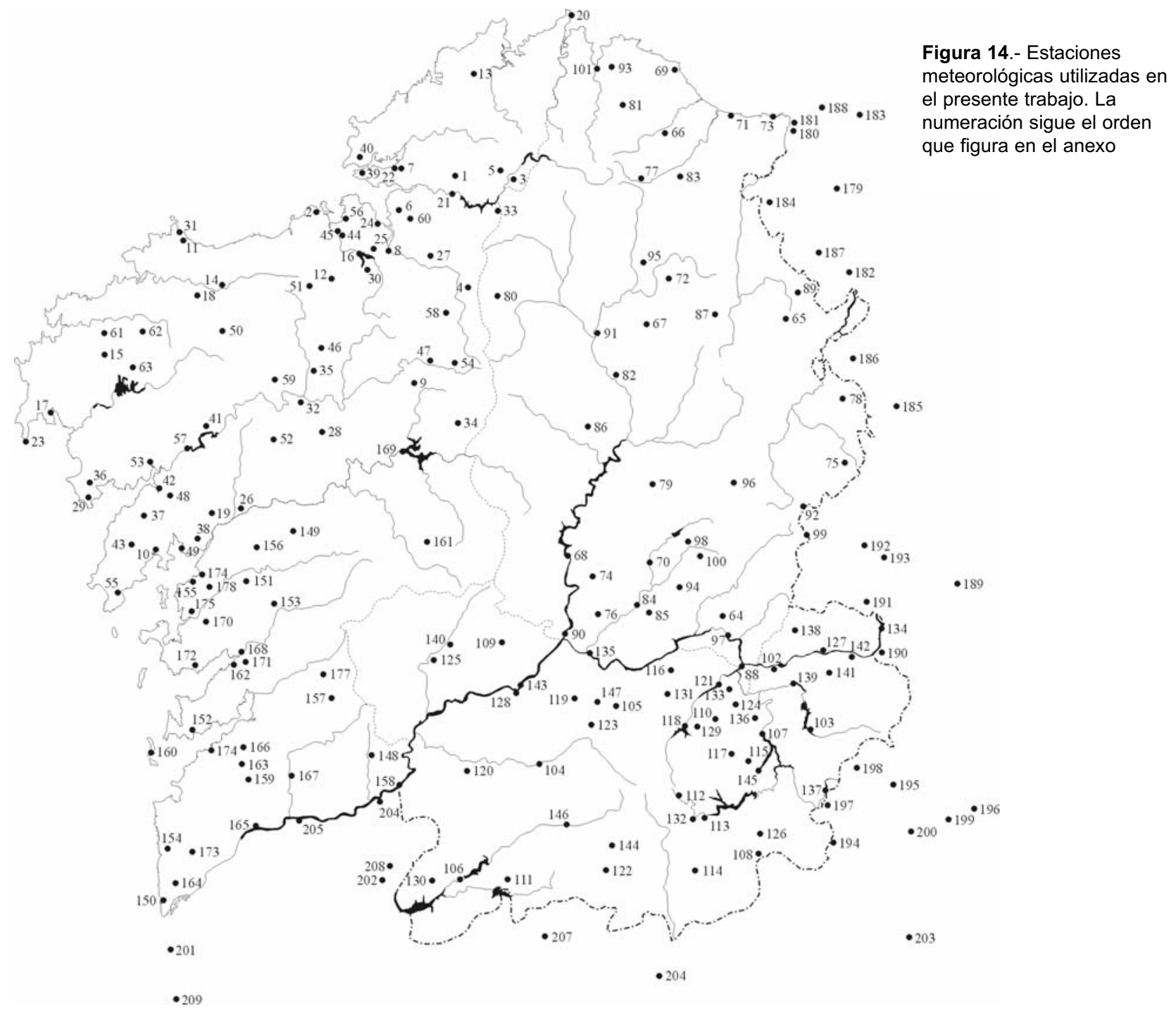


datos climáticos recogidos en 209 estaciones meteorológicas, situadas en territorio gallego y áreas limítrofes asturianas, castellano-leonesas y portuguesas (Figura 14), la metodología propuesta por Rivas-Martínez (2007). La procedencia de la información de base ha sido muy heterogénea, ya que se ha utilizado tanto información de carácter bibliográfico (Carballeira et al. 1983, García Rio \& Navarro Andrés 1994) como otra elaborada de manera específica para este trabajo a partir de la información proporcionada por la antigua Red de Estaciones Meteorológicas del CIFOR-Lourizán y el Instituto Nacional de Meteorología. En estos últimos casos, se han utilizado siempre series de datos que tuviesen, cuando menos, diez años de registro.

Según la clasificación bioclimática comentada, la diagnosis completa del bioclima de una estación meteorológica (y por extensión del territorio adyacente que presente una homología en sus condiciones climáticas con ésta) necesita del cálculo previo de los índices que se detallan a continuación:

-Índices ombrotérmicos (lo, $\left.\operatorname{los}_{2}, \operatorname{los}_{3}, \operatorname{los}_{4}\right)$ : mediante su cálculo se determina el tipo de macrobioclima (templado típico, templado submediterráneo o mediterráneo) así como el ombrotipo de una estación (valores de lo, Tabla 1). La determinación del macrobioclima en áreas climáticas de transición precisa del cálculo de los denominados "índices ombrotérmicos estivales compensables" $\left(\operatorname{los}_{2}, \operatorname{los}_{3}, \operatorname{los}_{4}\right)$ para determinar la pertenencia al tipo templado submediterráneo (cuando se alcancen o superen los valores de compensación) o mediterráneo (en caso contrario)(Tabla 2).

\begin{tabular}{lc}
\hline Ombrotipo & Valor de lo \\
\hline \hline Ultrahiperhúmed & $>24,0$ \\
\hline Hiperhúmedo superior & $>18,0-24,0$ \\
\hline Hiperhúmedo inferior & $>12,0-18,0$ \\
\hline Húmedo superior & $>9,0-12,0$ \\
\hline Húmedo inferior & $>6,0-9,0$ \\
\hline Subhúmedo superior & $>4,8-6,0$ \\
\hline Subhúmedo inferior & $>3,6-4,8$ \\
\hline
\end{tabular}

Tabla 1.- Valores umbrales de los ombrotipos presentes en Galicia

-índice ombrotérmico anual: $\mathrm{Io}=\mathrm{Pp} / \mathrm{Tp}$

siendo Pp: precipitación anual de los meses con $t>$ $0^{\circ} \mathrm{C}$

y Tp: suma de temperaturas medias mensuales > $0^{\circ} \mathrm{C} \times 10$

\begin{tabular}{cccc}
\hline lo & los $_{2}$ & los $_{3}$ & los $_{4}$ \\
\hline $3.6-4.8$ & $>1.8$ & $>1.9$ & $>2.0$ \\
\hline $4.8-6.0$ & $>1.7$ & $>1.8$ & $>2.0$ \\
\hline $6.0-8.0$ & $>1.7$ & $>1.8$ & $>2.0$ \\
\hline $8.0-10.0$ & $>1.6$ & $>1.7$ & $>2.0$ \\
\hline $10.0-12.0$ & $>1.4$ & $>1.7$ & $>2.0$ \\
\hline$>12.0$ & $>1.0$ & $>1.6$ & $>2.0$ \\
\hline
\end{tabular}

Tabla 2.-Valores de compensación de los índices ombrotérmicos estivales(las estaciones que los cumplen son templadas de carácter submediterráneo)

$$
\begin{aligned}
& \text {-índices ombrotérmicos estivales compensables: } \\
& \begin{array}{ll}
\operatorname{los}_{2} & =\text { Pjul+Pago/tjul-tago } \\
\operatorname{los}_{3} & =\text { Pjun+Pjul+Pago/tjun-tjul+tago } \\
\operatorname{los}_{4} & =\text { Pmay+Pjun+Pjul+ Pago/tmay+tjun-tjul+tago }
\end{array}
\end{aligned}
$$

-Índice de continentalidad (Ic): viene a corresponder con el valor de amplitud térmica media de una localidad y se utiliza para deteminar su tipo de bioclima. La fórmula de cálculo y los valores de los respectivos tipos de bioclima presentes en Galicia figuran en la Tabla 3.

-Índice de termicidad compensado (Itc): permite determinar el termotipo o piso bioclimático de una localidad a partir del cálculo del índice de termicidad simple (It). El cálculo del índice Itc tiene en cuenta el tipo de bioclima de la localidad, de manera que si este es de tipo oceánico, su valor es igual al del índice It; por el contrario si se trata de un área hiperoceánica o semicontinental (con valores de Ic inferiores a 8 o superiores a 17 respectivamente) es necesario sustraer o adicionar a it un "valor de compensación" (C) cuyo cálculo se detalla en la Tabla 4. Los intervalos de valores que definen cada uno de los termotipos presentes en Galicia se presentan en la Tabla 5.

A partir de la base de datos climáticos de partida se procedió al cálculo de los índices comentados como paso previo al establecimiento de la diagnosis bioclimática de las 209 estaciones meteorológicas empleadas (ver Anexo de estaciones meteorológicas). Una vez realizados los cálculos comentados y teniendo en cuenta los rangos numéricos que se establecen como límites entre las diferentes categorías bioclimáticas contempladas en esta clasificación, se procedió a una delimitación geográfica manual tentativa de los tipos de macrobioclimas, bioclimas, termotipos y ombrotipos representados en el territorio objeto de estudio y que aparecen representados de manera gráfica en las figuras 15 a 18. Los resultados obtenidos se comentan a continuación de forma pormenorizada.

\begin{tabular}{c|l|c}
\hline \multirow{2}{*}{$\begin{array}{c}\text { Ic } \text { (indice de continentalidad) } \\
\text { Ic }=\mathrm{tc}-\mathrm{tf} \text { siendo } \mathrm{tc}=\text { temperatura media del mes más } \\
\text { cálido } \mathrm{y} t \mathrm{t}=\mathrm{temperatura} \text { media del mes más frio. }\end{array}$} & \multicolumn{2}{|c}{ Subtipos } \\
\hline \multirow{2}{*}{$\mathrm{Ic}<11$ : bioclima hiperoceánico } & Euhiperoceánico & $<8,1$ \\
\cline { 2 - 3 } & Subhiperoceánico & $>8,0-11,0$ \\
\hline \multirow{2}{*}{$\mathrm{Ic}=11-18:$ bioclima oceánico } & Semihiperoceánico & $>11,0-14,0$ \\
\cline { 2 - 3 } & Euoceánico & $>14,0-17,0$ \\
\hline $\mathrm{Ic} \geq 18:$ bioclima continental & Semicontinental & $>17,0-21,0$ \\
\hline
\end{tabular}

Tabla 3.- Fórmula de cálculo del índice lc e intervalos numéricos que definen los tipos de bioclima presentes en Galicia 


\begin{tabular}{|c|c|c|c|c|}
\hline Macroclima & Termotipo & Horizonte & Valor de Itc & Valor de Tp \\
\hline \multirow{5}{*}{ Templado } & Termotemplado & $\begin{array}{l}\text { inferior } \\
\text { superior }\end{array}$ & $\begin{array}{c}>350 \\
290-350\end{array}$ & $\begin{array}{c}>2350 \\
2176-2350\end{array}$ \\
\hline & Mesotemplado & $\begin{array}{l}\text { inferior } \\
\text { superior }\end{array}$ & $\begin{array}{l}240-290 \\
190-240\end{array}$ & $\begin{array}{l}2000-2175 \\
1700-2000\end{array}$ \\
\hline & Supratemplado & $\begin{array}{l}\text { inferior } \\
\text { superior }\end{array}$ & $\begin{array}{c}<190 \\
\cdots\end{array}$ & $\begin{array}{l}1400-1700 \\
1100-1400\end{array}$ \\
\hline & Orotemplado & $\begin{array}{l}\text { inferior } \\
\text { superior }\end{array}$ & $\cdots$ & $\begin{array}{c}800-1100 \\
590-800\end{array}$ \\
\hline & Criorotemplado & inferior & $\ldots$ & $<590$ \\
\hline Mediterráneo & Mesomediterráneo & $\begin{array}{l}\text { inferior } \\
\text { superior }\end{array}$ & $\begin{array}{c}>285 \\
220-285\end{array}$ & $\begin{array}{c}>1800 \\
1500-1800\end{array}$ \\
\hline
\end{tabular}

\begin{tabular}{|c|}
\hline $\begin{array}{l}\text { It (indice de termicidad) } \\
\qquad \mathrm{t}=(\mathrm{M}+\mathrm{m}+\mathrm{T}) \times 10\end{array}$ \\
\hline Si Ic $\leq 8$, Itc $=I t-C$, siendo $C=(8-I c) \times 10$ \\
\hline Si Ic $\geq 17$, Itc $=I t+C$, siendo $C=(I c-17) \times 5$ \\
\hline Itc $=$ It si $11<$ Ic $<17$ \\
\hline
\end{tabular}

Tabla 4.- Fórmula de cálculo del índice Itc a partir del índice It en función de los valores del índice Ic

\section{Macrobioclimas}

Según la clasificación empleada, Galicia es un territorio comprendido dentro de la cintura latitudinal a través de la que se extiende el denominado "Macrobioclima Templado" (entre $23^{\circ}-51^{\circ} \mathrm{N}$ ), caracterizado por la ausencia o escasa incidencia de sequía estival. Intercalado en diferentes áreas del Planeta dentro del intervalo comentado se encuentra el "Macrobioclima Mediterráneo", diferenciable del primero por la existencia de un período de más de dos meses de sequía $(t>2 P)$ durante la estación de temperaturas medias mensuales más elevadas (verano). A lo largo de las áreas en las que se establece el contacto entre ambos tipos de macrobioclima existe un gradiente de situaciones intermedias representado por aquellas estaciones templadas en las que se registra un período de sequía que no alcanza la duración mínima exigida para poder ser consideradas como mediterráneas y que constituyen lo que se denomina "variante submediterránea" del macrobioclima templado (Figura 15).

En función de los datos climáticos disponibles y de la cartografía aquí presentada, se establece un claro dominio del macrobioclima templado en el territorio gallego, si bien algunas áreas geográficas situadas en el extremo SE (Cañon del Sil, Val de Quiroga y Valdeorras) se verifica la existencia del macrobioclima mediterráneo. Debido a esta condición de contacto entre los dos macrobioclimas comentados, y como ya señalamos con anterioridad, en una proporción elevada de estaciones meteorológicas templadas se aprecia la tendencia a presentar un corto período de sequía estival, por lo que se incluyen en la variante denominada "submediterránea" de dicho macrobioclima (Anexo).

Aunque numerosos autores han planteado la existencia de condiciones climáticas de mediterraneidad más o menos manifiestas en Galicia, entre ellos el propio autor de la clasificación bioclimática aquí aplicada, los resultados obtenidos restringen en una proporción muy elevada la superficie considerada como mediterránea en este terriorio que viene a coincidir, en línea generales, con las áreas de presencia generalizada de vegetación termófila esclerófila, principalmente encinares de Quercus ilex ssp. ballota y alcornocales no litorales. Por otra parte, la estación de Illas Cíes resulta clasificada, al igual que acontece en otros tipos de metodologías aplicadas a Galicia, como de carácter mediterráneo, hecho que, desde nuestro punto de vista, es consecuencia de su caracter insular, ya que no tiene efectos generalizados sobre su flora y características de su cubierta vegetal, semejantes en todo punto a las existentes en las áreas continentales más próximas.

De la misma manera, al igual que es frecuente encontrar taxones de distibución mediterránea en áreas próximas de macrobioclima templado, especies de distribución preferentemente atlántica están presentes dentro de las áreas que, según esta metodología, se consideran comprendidas dentro del macrobioclima mediterráneo, contraviniendo las clasificaciones obtenidas a partir de los datos climáticos. Así, por ejemplo, es posible encontrar dentro de las áreas mediterráneas de Galicia taxones vegetales característicos de la fachada atlántica europea (cf. Dupont 1966), como es el caso de Ulex europaeus, Daboecia cantabrica, Lithodora prostrata, Pseudarrhenatherum longifolium, Agrostis curtisii, Quercus robur, Betula alba, etc., presentes en diversas localidades de la Ribeira Sacra, Val de Quiroga o Valdeorras.

Este tipo de situaciones es perfectamente comprensible si se tiene en cuenta la posición bioclimática fronteriza del territorio gallego y la gran sensibilidad que este tipo de territorios tienen y han tenido con respecto a los cambios climáticos que han acontecido en la historia geológica más reciente (Pleistoceno-Holoceno). Todo ello indica, desde nuestro punto de vista, un cierto carácter marginal del macrobioclima mediterráneo en Galicia. Esta consideración es acorde con la escasa representación que las formaciones esclerófilas, como elementos dominantes en el paisaje, han tenido en este ámbito geográfico, y en el NW Ibérico en general, a lo largo de los últimos 10.000 años, tal y como han demostrado diversos estudios paleobotánicos (cf. Ramil-Rego et al. 1998; Alcalde Olivares et al. 2004, López de Heredia et al. 2007). Ello plantea una interesante incógnita sobre el origen y vías de colonización seguidas por la flora que actualmente se considera integrante de las comunidades vegetales presentes en las áreas de clima mediterráneo en Galicia y su prolongación, Sil arriba, por la comarca leonesa de El Bierzo, cuestión que hasta el momento solamente ha sido abordada desde una perspectiva exclusivamente florística (cf. Izco et al. 1986, Izco 1989). 

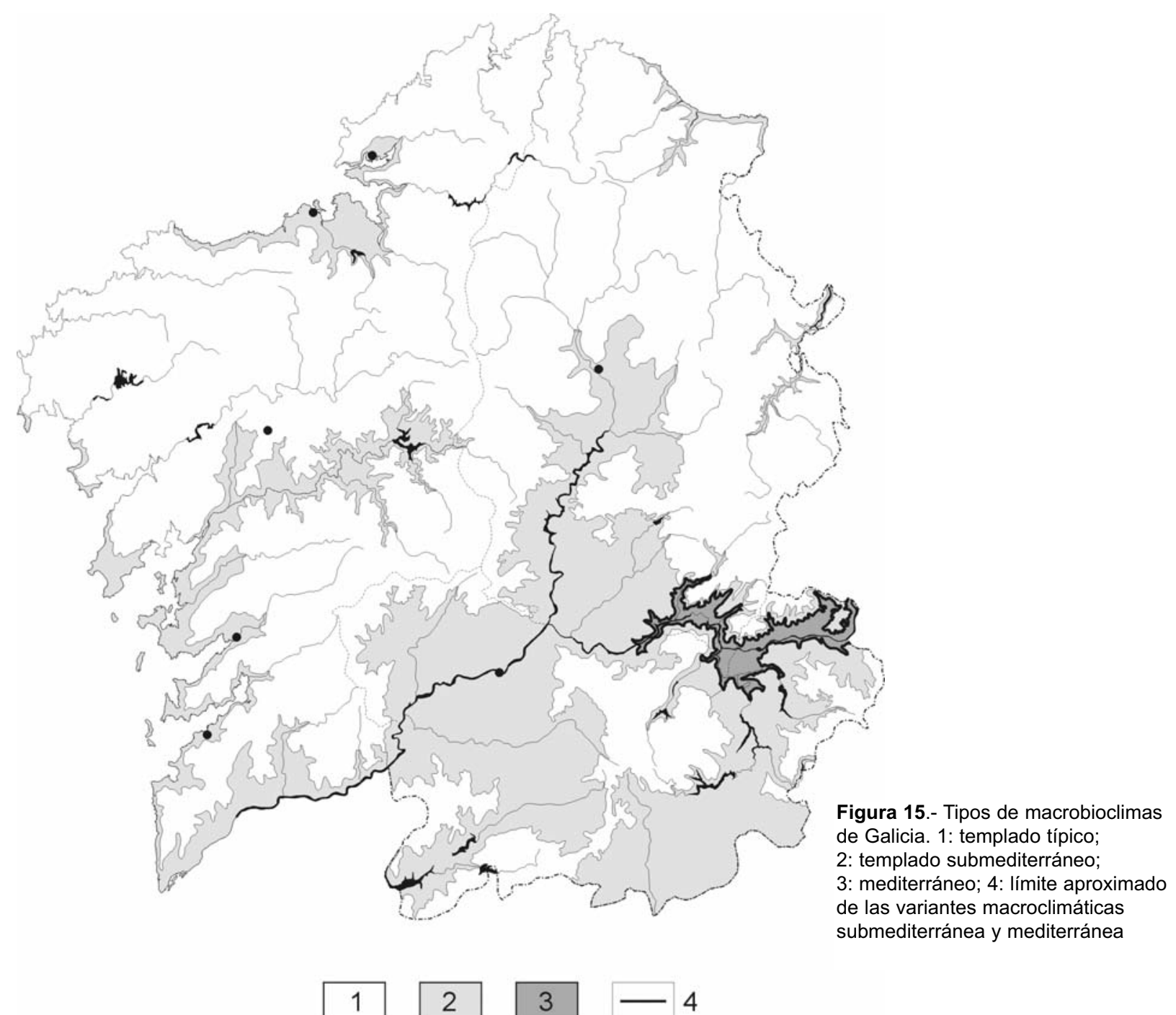

\section{Bioclimas}

Como es sabido, las masas de agua marina ejercen un efecto atemperante en el clima de las tierras emergidas que las circundan observándose una tendencia progresiva a la continentalización conforme nos alejamos de las costas. Desde el punto de vista termométrico, este fenómeno se pone claramente de manifiesto a través del incremento de la amplitud térmica (diferencia entre las temperaturas medias del més más frío y del mes más cálido) que se experimenta desde el litoral hacia las áreas interiores y permite explicar la distribución preferentemente costera de determinados grupos florísticos y comunidades vegetales poco tolerantes a los climas contrastados, cuya presencia no es posible en áreas más continentales. Además, las altas tasas de evaporación que se producen en los mares a lo largo de la época estival aportan un elevado grado de humedad a las costas, efecto que se pierde progresivamente hacia el interior, en donde el aire tiende a presentar una humedad relativa sensiblemente inferior en todas la épocas de año, provocando un aumento de las tasas de transpiración en los vegetales.
La influencia de las masa oceánicas en el clima se determina en la clasificación bioclimática aquí seguida mediante el denominado "índice de continentalidad" (Ic), equivalente al valor de la amplitud térmica media anual, que se calcula como la diferencia de temperaturas medias mensuales de los meses más cálido y más frío. En función del valor que alcance este índice se establecen diversos tipos de bioclima dentro de algunos macrobioclimas, entre los que se encuentran el templado y el mediterráneo.

Los resultados obtenidos en el caso de Galicia muestran que las áreas cercanas al Mar Cantábrico y al Océano Atlántico se encuentran bajo un bioclima de carácter hiperoceánico, con temperaturas medias mensuales que sufren variaciones poco marcadas a lo largo del año (inferiores a $11^{\circ} \mathrm{C}$ ). No obstante, se observa una reducción progresiva de $\mathrm{N}$ a $\mathrm{S}$ del territorio incluído en este tipo de bioclima asociado al incremento del valor del índice Ic que produce la existencia de veranos más calurosos en el litoral de las Rías Baixas. Por su parte, la Galicia interior presenta una menor influencia de las masas marinas en el clima (bioclimas semihiperoceánico y euoceánico), dado que los inviernos son algo rigurosos y los veranos tienden a ser más 
calurosos que en la costa. Aunque conforme nos trasladamos hacia el extremo SE del país se incrementa notablemente la amplitud térmica, solamente se alcanzan valores incluibles dentro del subtipo semicontinental en el tramo de cabecera de la cuenca del Rio Bibei, por encima de los $1.000 \mathrm{~m}$ de altitud (Figura 16).

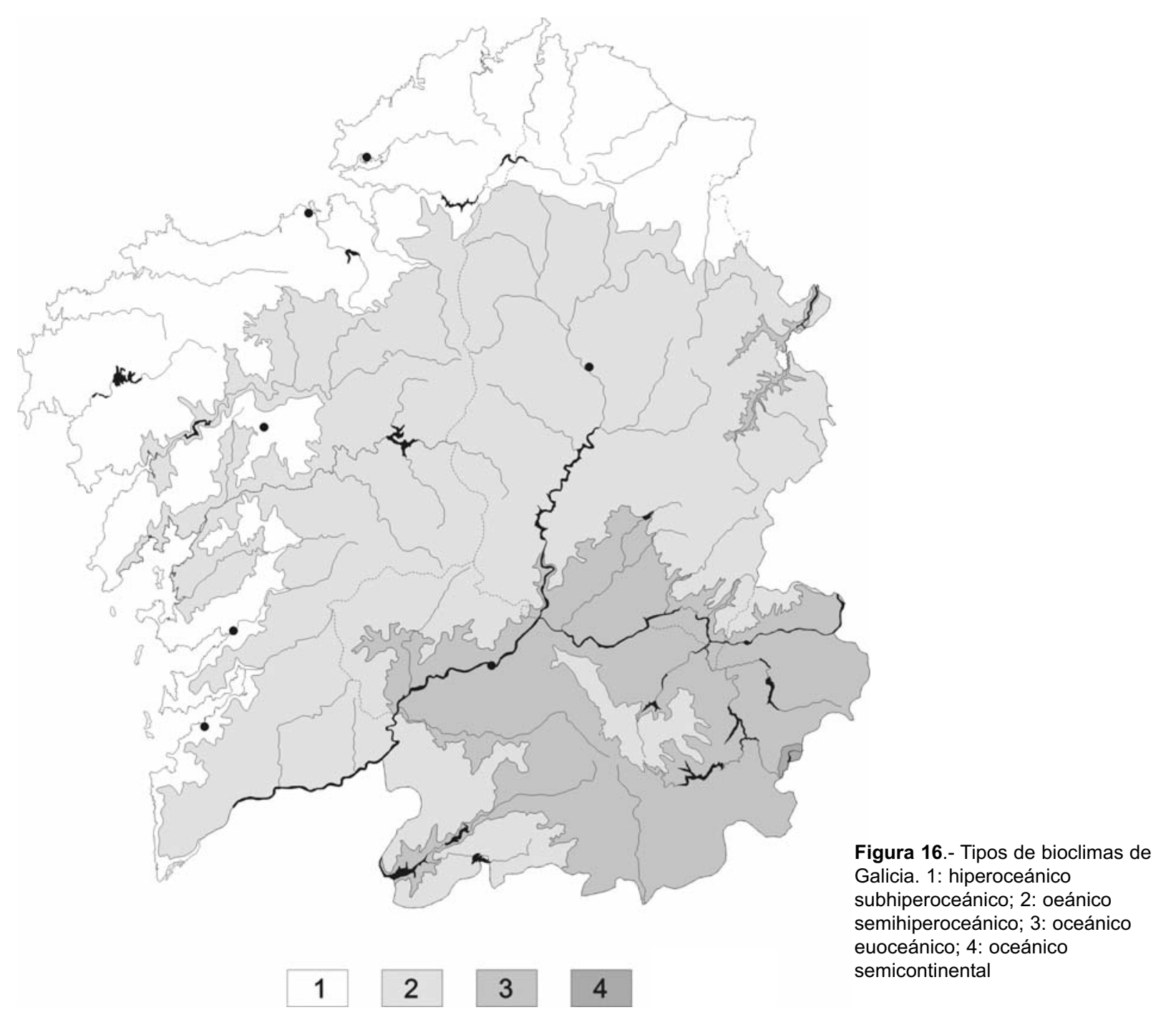

\section{Termotipos (pisos bioclimáticos)}

Se entiende como termotipo o piso bioclimático un intervalo altitudinal, caracterizado por unos valores termométricos determinados, al que se asocian uno o varios tipos de vegetación característicos. El número y distribución altitudinal de intervalos termométricos definibles es diferente en los distintos tipos de macrobioclimas y variantes bioclimáticas, habiéndose establecido para el caso de la Península Ibérica un total de cinco en las áreas bajo macrobioclima templado y seis en las mediterráneas (Tabla 5). Según los datos climáticos disponibles se admite para Galicia la existencia de cinco termotipos templados (termotemplado, mesotemplado, supratemplado y orotemplado) y uno mediterráneo (mesomediterráneo) cuya distribución geográfica aparece reflejada en la Figura 15.
A través de la experiencia acumulada en más de siglo y medio de estudios de la cubierta vegetal del territorio gallego y áreas peninsulares próximas, se sabe que la distribución geográfica de los distintos termotipos presenta una buena correlación con la de algunos taxones vegetales de manera que, en ausencia de estaciones meteorológicas, es posible determinar de manera bastante aproximada el piso bioclimático de un determinado territorio examinando en detalle su flora. En la Tabla 6 se muestran las principales especies leñosas que presentan un comportamiento bioclimático fiable como indicadores del tipo del termotipo de una localidad dentro del ámbito gallego. Hay que destacar con respecto a las plantas marcadamente termófilas, no obstante, que su distribución tiende a ser contínua en los termotipos más benignos, con independencia de que se trate de territorios eurosiberianos o mediterráneos. Tal es el caso de taxones como Quercus 


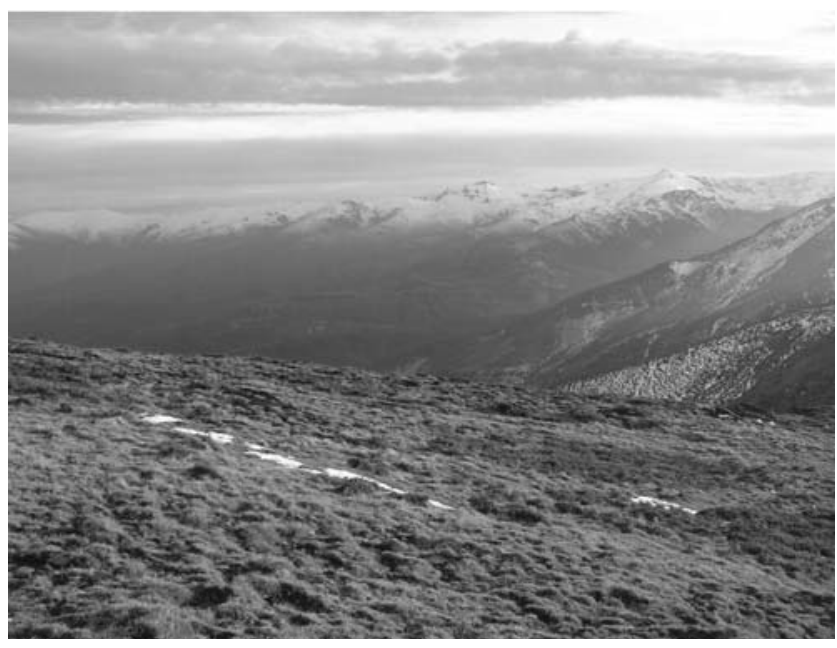

Fotografía 1.- La existencia de un acentuado rigor invernal es una de las principales características bioclimáticas de las áreas montañosas surorientales de Galicia. Alto de Fonte da Coba, Macizo de Trevinca (Carballeda de Valdeorras, Ourense)

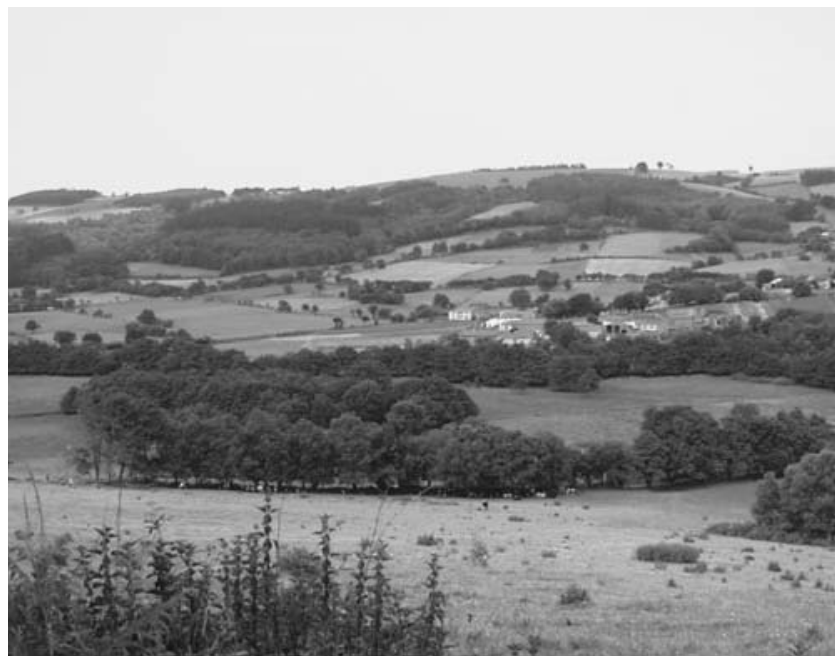

Fotografía 3.-La mayor parte del territorio gallego se encuentra incluido dentro del termotipo mesotemplado en el que, a pesar de existir un período invernal bien marcado, el clima no es especialmente riguroso. Valle de Ferreiros (Pol, Lugo)

suber, Osyris alba, Daphne gnidium, Arbutus unedo, Cistus psilosepalus o $C$. salvifolius, comunes tanto en los pisos termotemplado y mesotemplado inferior como en el mesomediterráneo.

El termotipo mesotemplado es el más ampliamente distribuido por Galicia y dentro de él se pueden distinguir dos horizontes: inferior y superior. El primero se sitúa inmediatamente por encima del termotemplado, hasta niveles que oscilan entre los $400-450 m$ en la mitad septentrional y alrededor de los 550-600 en la meridional, mientras que el segundo no suele rebasar los $700-800 \mathrm{~m}$ en prácticamente todo el territorio gallego, si se exceptúan las montañas orientales ourensanas, en las que el efecto de continentalidad provoca un ascenso apreciable de las temperaturas estivales y permite su extensión hasta altitudes próximas a los $1.000 \mathrm{~m}$. En este piso bioclimático

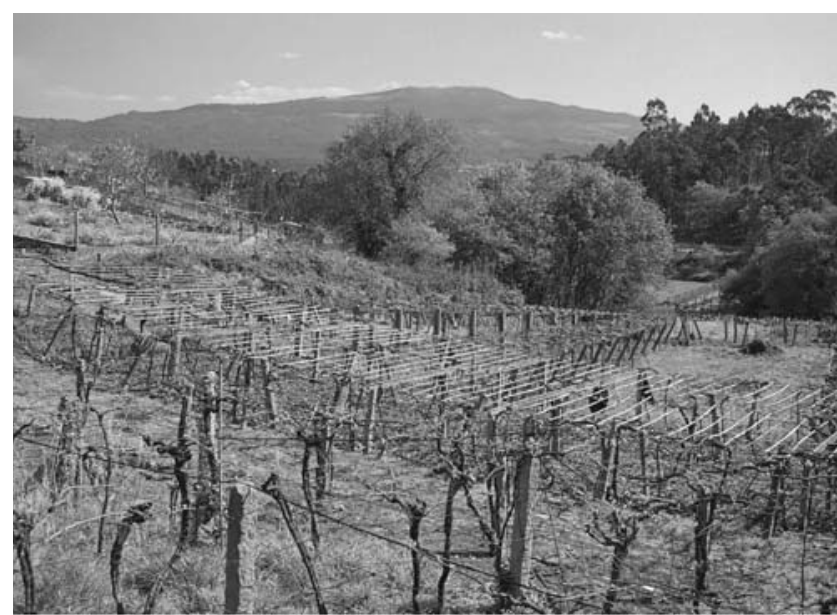

Fotografía 2.- Las áreas gallegas próximas a la costa se caracterizan por un clima benigno de inviernos suaves (termotipo termotemplado) que permite el cultivo de numerosas especies de amplia distribución en los paises de la cuenca mediterránea. Viñedos en la Ría de Arousa (Bexo, Dodro, A Coruña)

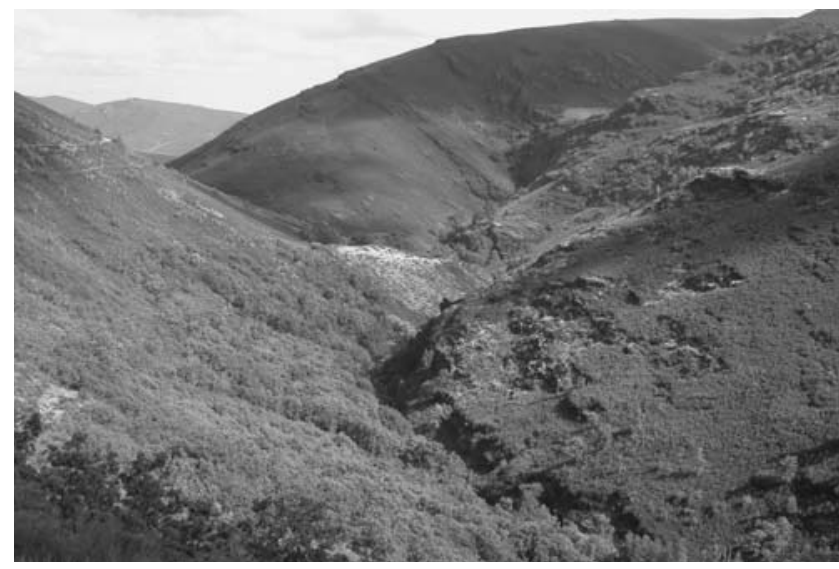

Fotografía 4.- Las montañas más elevadas de Galicia albergan la mayor parte de las áreas incluidas en el termotipo supratemplado. En estas zonas, los asentaminetos humanos permanentes son escasos y predominan las áreas cubiertas por matorrales, masas forestales dominadas por especies autóctonas y repoblaciones forestales de pinos. Valle del Río Cerveira (Vilariño de Conso, Ourense)

ya se registran condicionantes climáticos severos para el cultivo de numerosas especies de carácter termófilo, si bien el grado de limitación puede variar sensiblemente entre los dos horizontes descritos, en función de la incidencia de otros factores climáticos (nubosidad, reparto estival de la precipitación, grado de continentalidad, etc.).

Taxones vegetales indicadores del horizonte mesotemplado inferior, también presentes por lo general, como ya se indicó, dentro del termotemplado, son Cistus psilosepalus, Arbutus unedo, Rubia peregrina, Laurus nobilis y Adenocarpus lainzii; alcanzan el límite superior de su distribución natural en el horizonte superior de este piso bioclimático taxones como Castanea sativa, Quercus robur, Ulex europaeus, Tamus communis y Ruscus aculeatus, entre otros. 

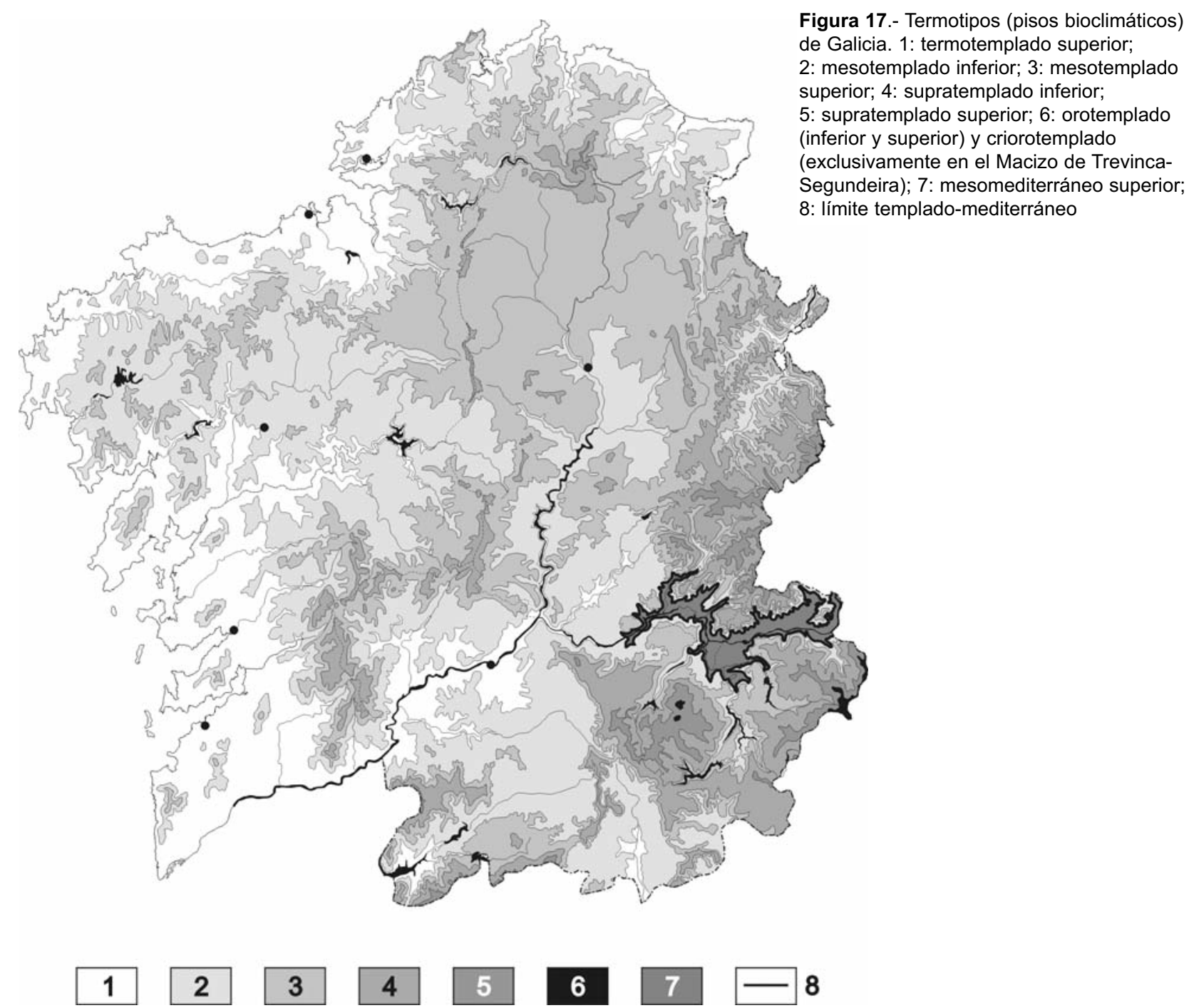

Los territorios supratemplados gallegos alcanzan una reducida extensión en comparación con otras áreas septentrionales de la Península lbérica, ciñéndose a las cotas más elevadas de los sistemas montañosos que conforman la denominada Dorsal Gallega y las Sierras Septentrionales, Orientales y Meridionales (Figura 17). En la parte central de Galicia el límite inferior de este piso bioclimático suele encontrarse alrededor de los 750-800m de altitud, nivel que desciende hasta cerca de los $650 \mathrm{~m}$ en las sierras más elevadas del macizo de O Xistral debido a la fuerte oceaneidad del clima, mientras que, contrariamente, asciende hasta situarse entorno a los $1.000-1.100 \mathrm{~m}$ en las sierras del centro-oriente ourensano.

Como en el caso del piso mesotemplado se pueden diferenciar dos horizontes, uno inferior que contacta con el mesotemplado superior y se extiende aproximadamente hasta los $1.200-1.350 \mathrm{~m}$ y otro (supratemplado superior) desde esta cota hasta los $1.650-1.700 \mathrm{~m}$. Aunque este piso bioclimático está representado en casi todos los sistemas montañosos de Galicia, es en las montañas orientales y en las meridionales ourensanas donde cubre una mayor extensión.
El período libre de heladas en este piso bioclimático es muy reducido, sobre todo en el horizonte superior, lo que ha limitado tradicionalmente la existencia de asentamientos humanos en este termotipo a las áreas de clima más benigno situadas dentro del horizonte inferior. Consecuentemente, los aprovechamientos tradicionales de estos territorios se han limitado al pastoreo estacional con ganado vacuno, caballar, ovino y caprino y el abastecimiento de leñas para combustible y madera con finalidad constructiva. Diversas especies vegetales encuentran en Galicia el óptimo ambiental para su desarrollo en las condiciones bioclimáticas características de este termotipo. Entre ellas se pueden destacar Aconitum vulparia subsp. neapolitanum, Actaea spicata, Corydalis cava, Daphne laureola, Fagus sylvatica, Galium odoratum, G. rotundifolium, Paris quadrifolia, Quercus petraea, Ranunculus platanifolius, Trollius europaues, Salix caprea, Sorbus aria, Sorbus aucuparia o Taxus baccata.

En los macizos montañosos más elevados de Galicia se observa que la vegetación arbolada de carácter climácico adquiere progresivamente una menor talla y un porte más tortuoso conforme se aproxima a una cota comprendida 


\begin{tabular}{|c|c|c|c|c|c|c|c|c|}
\hline \multirow{2}{*}{\multicolumn{2}{|c|}{ Taxón }} & \multicolumn{7}{|c|}{ Termotipo } \\
\hline & & Mms & $\mathrm{Tt}$ & Mti & Mts & Sti & Sts & Ot \\
\hline \multicolumn{2}{|l|}{ Acer monspessulanum } & $\odot$ & $\cdots$ & $\ldots$ & $\cdots$ & $\ldots$ & $\ldots$ & $\cdots$ \\
\hline \multicolumn{2}{|l|}{ Arbutus unedo } & - & - & - & $\odot$ & ... & ... & $\cdots$ \\
\hline \multicolumn{2}{|l|}{ Berberis vulgaris } & $\cdots$ & $\ldots$ & $\ldots$ & $\cdots$ & $\odot$ & $\ldots$ & $\cdots$ \\
\hline \multicolumn{2}{|l|}{ Castanea sativa } & $\bullet$ & $\bullet$ & $\bullet$ & $\bullet$ & $\odot$ & ... & $\cdots$ \\
\hline \multicolumn{2}{|l|}{ Celtis australis } & $\odot$ & $\odot$ & $\ldots$ & $\ldots$ & $\ldots$ & $\ldots$ & $\cdots$ \\
\hline \multicolumn{2}{|l|}{ Cistus ladanifer } & $\bullet$ & $\ldots$ & $\ldots$ & $\cdots$ & $\ldots$ & $\ldots$ & $\cdots$ \\
\hline \multicolumn{2}{|l|}{ Cistus populifolius } & - & $\odot$ & $\ldots$ & $\cdots$ & $\cdots$ & $\ldots$ & $\cdots$ \\
\hline \multicolumn{2}{|l|}{ Cistus psilosepalus } & - & - & $\odot$ & $\cdots$ & $\ldots$ & ... & $\cdots$ \\
\hline \multicolumn{2}{|l|}{ Cistus salvifolius } & - & $\odot$ & ... & ... & ... & ... & $\cdots$ \\
\hline \multicolumn{2}{|l|}{ Clematis vitalba } & $\bullet$ & $\bullet$ & $\bullet$ & $\odot$ & $\ldots$ & $\ldots$ & $\cdots$ \\
\hline \multicolumn{2}{|l|}{ Cytisus oromediterraneus } & $\cdots$ & $\ldots$ & $\cdots$ & $\cdots$ & $\cdots$ & $\ldots$ & $\odot$ \\
\hline \multicolumn{2}{|l|}{ Daphne gnidium } & $\odot$ & $\bullet$ & $\ldots$ & ... & $\ldots$ & $\ldots$ & $\ldots$ \\
\hline \multicolumn{2}{|l|}{ Dorycnium pentaphyllum } & $\odot$ & $\odot$ & $\ldots$ & $\cdots$ & $\ldots$ & $\ldots$ & $\cdots$ \\
\hline \multicolumn{2}{|l|}{ Echinospartum lusitanicum } & $\ldots$ & $\cdots$ & ... & $\ldots$ & $\odot$ & $\odot$ & $\ldots$ \\
\hline \multicolumn{2}{|l|}{ Erica scoparia } & $\bullet$ & $\odot$ & $\odot$ & $\ldots$ & $\ldots$ & ... & $\cdots$ \\
\hline \multicolumn{2}{|l|}{ Fagus sylvatica } & ... & ... & $\odot$ & $\odot$ & - & - & $\cdots$ \\
\hline \multicolumn{2}{|l|}{ Fraxinus angustifolia } & $\bullet$ & $\bullet$ & $\odot$ & $\cdots$ & $\ldots$ & $\ldots$ & ... \\
\hline \multicolumn{2}{|l|}{ Genista falcata } & $\bullet$ & $\odot$ & $\odot$ & $\ldots$ & $\cdots$ & ... & ... \\
\hline Genista hystrix & & $\bullet$ & $\odot$ & $\cdots$ & $\cdots$ & $\ldots$ & $\ldots$ & $\cdots$ \\
\hline Genista obtusiramea & & $\ldots$ & $\cdots$ & $\cdots$ & $\cdots$ & $\cdots$ & $\odot$ & $\bullet$ \\
\hline Genista sanabrensis & & $\cdots$ & $\cdots$ & $\ldots$ & $\ldots$ & $\ldots$ & $\odot$ & $\bullet$ \\
\hline Genista triacanthos & & $\cdots$ & $\odot$ & $\odot$ & $\cdots$ & $\cdots$ & $\ldots$ & $\cdots$ \\
\hline Humulus Iupulus & & $\odot$ & - & $\odot$ & ... & ... & ... & $\cdots$ \\
\hline Jasminum fruticans & & $\odot$ & $\cdots$ & $\ldots$ & $\cdots$ & $\ldots$ & $\cdots$ & $\cdots$ \\
\hline Juniperus communis subsp. al & & $\cdots$ & $\cdots$ & $\ldots$ & $\cdots$ & $\cdots$ & $\ldots$ & $\odot$ \\
\hline Laurus nobilis & & $\odot$ & $\bullet$ & $\bullet$ & $\odot$ & $\ldots$ & $\ldots$ & ... \\
\hline Lavandula stoechas subsp. sa & paioana & $\bullet$ & $\odot$ & $\odot$ & $\cdots$ & $\cdots$ & $\cdots$ & $\cdots$ \\
\hline Lavandula stoechas subsp. stc & chas & $\cdots$ & $\odot$ & $\ldots$ & $\ldots$ & $\ldots$ & $\ldots$ & ... \\
\hline Lonicera etrusca & & $\odot$ & $\cdots$ & $\cdots$ & $\cdots$ & $\cdots$ & $\cdots$ & $\cdots$ \\
\hline Olea europaea var. sylvestris & & $\odot$ & $\cdots$ & $\cdots$ & $\cdots$ & $\cdots$ & $\ldots$ & $\cdots$ \\
\hline Osyris alba & & $\bullet$ & $\odot$ & $\ldots$ & ... & ... & $\ldots$ & ... \\
\hline Phillyrea angustifolia & & $\bullet$ & $\cdots$ & ... & $\cdots$ & $\cdots$ & ... & ... \\
\hline Phillyrea latifolia & & $\bullet$ & $\odot$ & $\cdots$ & $\cdots$ & $\ldots$ & $\ldots$ & ... \\
\hline Prunus lusitanica & & $\odot$ & $\odot$ & $\ldots$ & $\ldots$ & $\ldots$ & $\ldots$ & ... \\
\hline Quercus ilex subsp. ballota & & - & $\odot$ & $\odot$ & $\odot$ & $\odot$ & $\ldots$ & ... \\
\hline Quercus robur & & $\bullet$ & $\bullet$ & - & $\bullet$ & $\odot$ & $\ldots$ & $\cdots$ \\
\hline Quercus suber & & - & - & $\odot$ & ... & ... & ... & $\cdots$ \\
\hline Rhamnus cathartica & & $\cdots$ & $\cdots$ & $\cdots$ & $\odot$ & $\odot$ & $\cdots$ & $\cdots$ \\
\hline Ribes petraeum & & $\cdots$ & $\ldots$ & $\ldots$ & $\ldots$ & $\odot$ & $\odot$ & ... \\
\hline Sorbus aria & & $\ldots$ & $\cdots$ & $\ldots$ & $\ldots$ & $\odot$ & $\odot$ & ... \\
\hline Sorbus aucuparia & & $\cdots$ & $\cdots$ & $\ldots$ & $\odot$ & $\bullet$ & $\bullet$ & $\cdots$ \\
\hline Sorbus intermedia & & $\cdots$ & $\ldots$ & $\cdots$ & $\ldots$ & $\ldots$ & $\odot$ & ... \\
\hline Ulex europaeus & & $\odot$ & $\bullet$ & $\bullet$ & $\bullet$ & $\ldots$ & ... & ... \\
\hline Vaccinium uliginosum & & $\cdots$ & $\cdots$ & ... & $\ldots$ & $\cdots$ & $\cdots$ & $\odot$ \\
\hline Viburnum lantana & & $\bullet$ & $\cdots$ & $\cdots$ & ... & $\cdots$ & $\cdots$ & $\cdots$ \\
\hline Viburnum opulus & & $\cdots$ & $\bullet$ & $\odot$ & $\odot$ & $\ldots$ & ... & $\cdots$ \\
\hline Taxón ausente & $\cdots$ & Presente & $\odot$ & & Abur & ante & $\bullet$ & \\
\hline
\end{tabular}

Tabla 6.- Rango termotípico de los principales taxones leñosos y lianoides con valor termoindicador presentes en Galicia entre los 1.650-1700m, a partir de la que prácticamente se extinguen los árboles. La desaparición en altitud de la vegetación arbolada por imperativos climáticos es característica del piso orotemplado en Galicia y las montañas de la Cordillera Cantábrica y se debe a la gran amplitud anual que presenta el período con probabilidad de heladas unida a unos valores bajos de la temperatura media anual. A pesar de que dentro del territorio gallego no existen estaciones meteorológicas por encima de $1.500 \mathrm{~m}$ de altitud, las situadas en montañas próximas permiten extrapolar la existencia de este piso bioclimático, aunque con una representación espacial muy restringida, al cordal de cumbres de la Serra de Ancares, el sector culminante del Macizo de Queixa y el área cimera de las sierras de Trevinca-Segundeira. Dentro de este último macizo montañoso podría admitirse la existencia del piso bioclimático crorotemplado para el sector de cumbres situado por encima de los $2100 \mathrm{~m}$. Determinados tipos de 


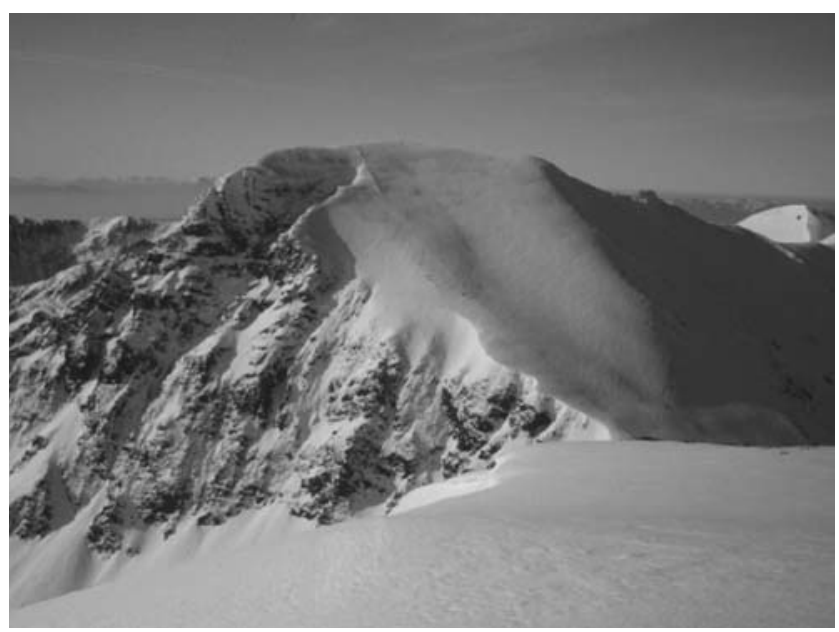

Fotografía 5.-Los sectores de cumbres de los principales sistemas montañosos de Galicia (Os Ancares, Manzaneda, Trevinca) presentan condiciones climáticas que impiden el desarrollo espontáneo de vegetación arbolada (termotipo orotemplado). Aspecto invernal del Pico Mostallar, máxima cumbre de la vertiente lucense de Os Ancares (Cervantes, Lugo), incluído íntegramente en el termotipo orotemplado

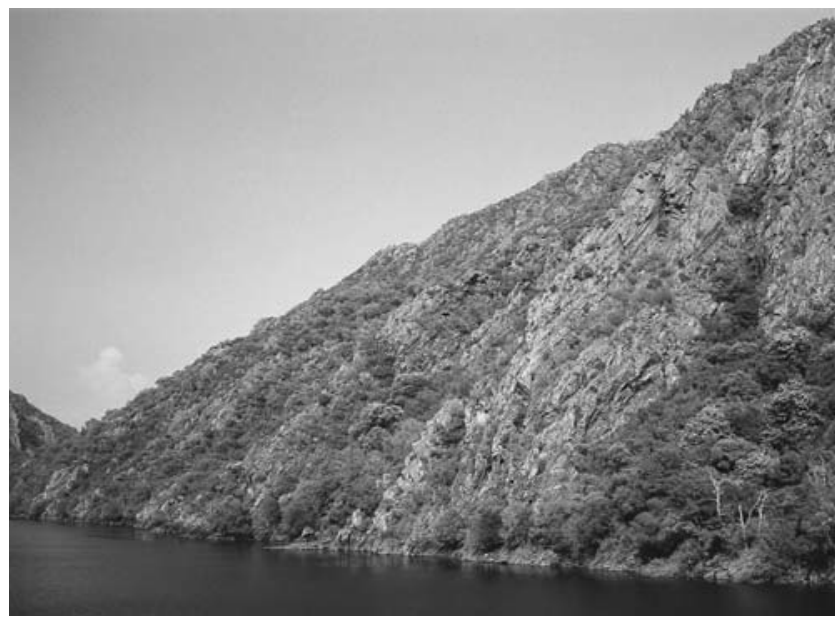

Fotografía 7.- El Canón do Sil presenta unas condiciones edafotopográficas y microclimáticas favorables para la presencia de especies termófilas de amplia distribución en el occidente de la cuenca Mediterránea, entre las que se encuentran $Q$. suber, $Q$. ballota, Phillyrea angustifolia, Pistacia terebinthus, Osyris alba, Cistus salvifolius, C. psilosepalus o Acer monspessulanum

vegetación que de forma natural se encuentran en estas montañas, como los piornales orófilos de Genista obtusiramea y Cytisus purgans, los enebrales rastreros con arándano negro (Juniperus communis subsp. alpina, Vaccinium uliginosum) y diversas comunidades herbáceas quionófilas o adaptadas a una fuerte croturbación permiten, en ausencia de datos climáticos, delimitar con cierta precisión la extensión de estos termotipos en Galicia a la vez que corroboran las deducciones obtenidas del análisis del comportamiento de las estaciones meteorológicas de su entorno.

Dentro de las áreas de macrobioclima mediterráneo existentes en Galicia se consideran únicamente

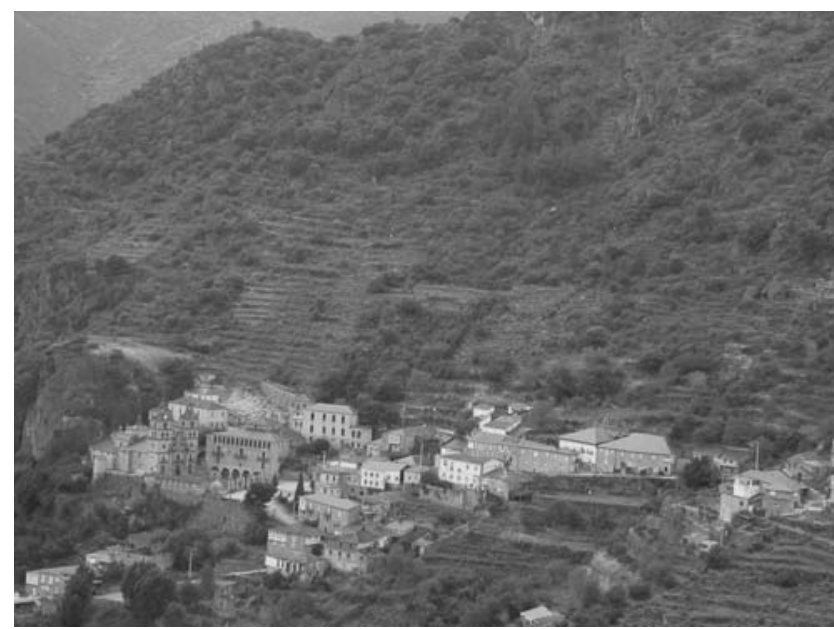

Fotografía 6.-El mosaico de pequeñas parcelas de cultivo, los viñedos ocupando bancales y los fragmentos de vegetación esclerófila (encinares, alcornocales, madroñales), junto a la abundancia de afloramientos rocosos, caracterizan una buena parte de las área mediterráneas de Galicia. As Ermitas ( $O$ Bolo, Ourense)

representado el termotipo mesomediterráneo que se extiende a lo largo de la mayor parte del tramo gallego del Río Sil y de su red de tributarios (Casaio, Bibei, Xares, Návea, Soldón, Quiroga, Lor) hasta las proximidades del embalse de San Estevo. En el extremo occidental de este territorio, este termotipo englobando las vertientes y fondos de valle situados por debajo de los 400/450 m de altitud y va ascendiendo progresivamente hacia el IE, en el límite con la comarca leonesa de El Bierzo, en donde llega a alcanzar los $650 / 700 \mathrm{~m}$.

La situación alejada del mar de estos territorios favorece la existencia de fenómenos de inversión térmica durante el invierno en los principales valles, con el consiguiente incremento del período probable de heladas con relación a las áreas de carácter templado más próximas. No obstante, este fenómeno no alcanza la suficiente intensidad y duración a lo largo del año como para limitar la presencia de especies, tanto silvestres como cultivadas, de temperamento termófilo que se distribuyen abundantemente como continuación hacia el interior gallego de lo señalado con anterioridad para las áreas termo y mesotempladas inferiores del dominio templado. La elevada termicidad estival que caracteriza estos territorios, junto al bajo aporte pluviométrico que se registra entre mayo y septiembre, favorece la presencia de plantas adaptadas a estas condiciones, entre las que se pueden destacar la encina (Quercus ilex subsp. ballota), el alcornoque ( $Q$. suber), el madroño (Arbutus unedo), las olivillas (Phillyrea angustifolia, P. latifolia), el escornacabras (Pistacia terebinthus) 0 el arce de Montpellier (Acer monspessulanum), entre otras muchas especies.

Las especiales características climáticas de las áreas mediterráneas gallegas, unidas a las que presenta el recurso suelo han obligado a la construcción de una cantidad ingente de bancales o "sucalcos" en los que se han venido cultivando, desde hace centurias, plantas leñosas 
como la vid, el castaño y el olivo, especies que, después de un prolongado período de declive registrado hasta mediados del pasado siglo, se encuentran actualmente en recuperación. Paralelamente y teniendo en cuenta la escasez de áreas aptas para la producción de heno, la ganadería más extendida ha sido la de ganado menor (ovejas, cabras) que encontraba abundante pasto principalmente en las áreas desarboladas cercanas a los pueblos.

\section{Ombrotipos}

Un parámetro que influye de manera decisiva en la distribución de las formaciones vegetales es la relación existente entre el régimen de temperaturas $y$ de precipitaciones a lo largo del año. Este aspecto es abordado en la clasificación de Rivas-Martínez (2007) a través de la determinación de los denominados "ombrotipos", para cada uno de los cuales, como en el caso de los termotipos, suelen diferenciarse sendos horizontes inferior y superior.
Los datos climáticos manejados permiten establecer la existencia de cuatro tipos ómbricos enel territorio gallego: subhúmedo, húmedo, hiperhúmedo y ultrahiperhúmedo, cuya distribución se muestra en la Figura 18. Como puede apreciarse, el tipo húmedo es el más ampliamente representado ocupando su horizonte inferior gran parte de las partes bajas litorales, valles sublitorales y depresiones interiores (Terra Chá, Terra de Lemos, Maceda, A Limia). Por su parte, en el horizonte superior se incluyen la mayoría de las áreas montañosas septentrionales y las tierras suavemente onduladas de las cabeceras del Tambre y Ulla. Igualmente pertenecen a este tipo ómbrico otras áreas elevadas de las sierras meridionales ourensanas y montañas medias de las Sierras Orientales de Lugo.

El ombrotipo subhúmedo está asociado básicamente a áreas que se encuentran protegidas de los vientos otoñales e invernales cargados de humedad, como la acontece en la Mariña Luguesa o en comarcas en las que el descenso de aporte hídrico en la época estival es más acusado, caso de las partes más externas de las Rías Baixas, la cuenca media y baja del Río Miño, gran parte de la cuenca del Cabe
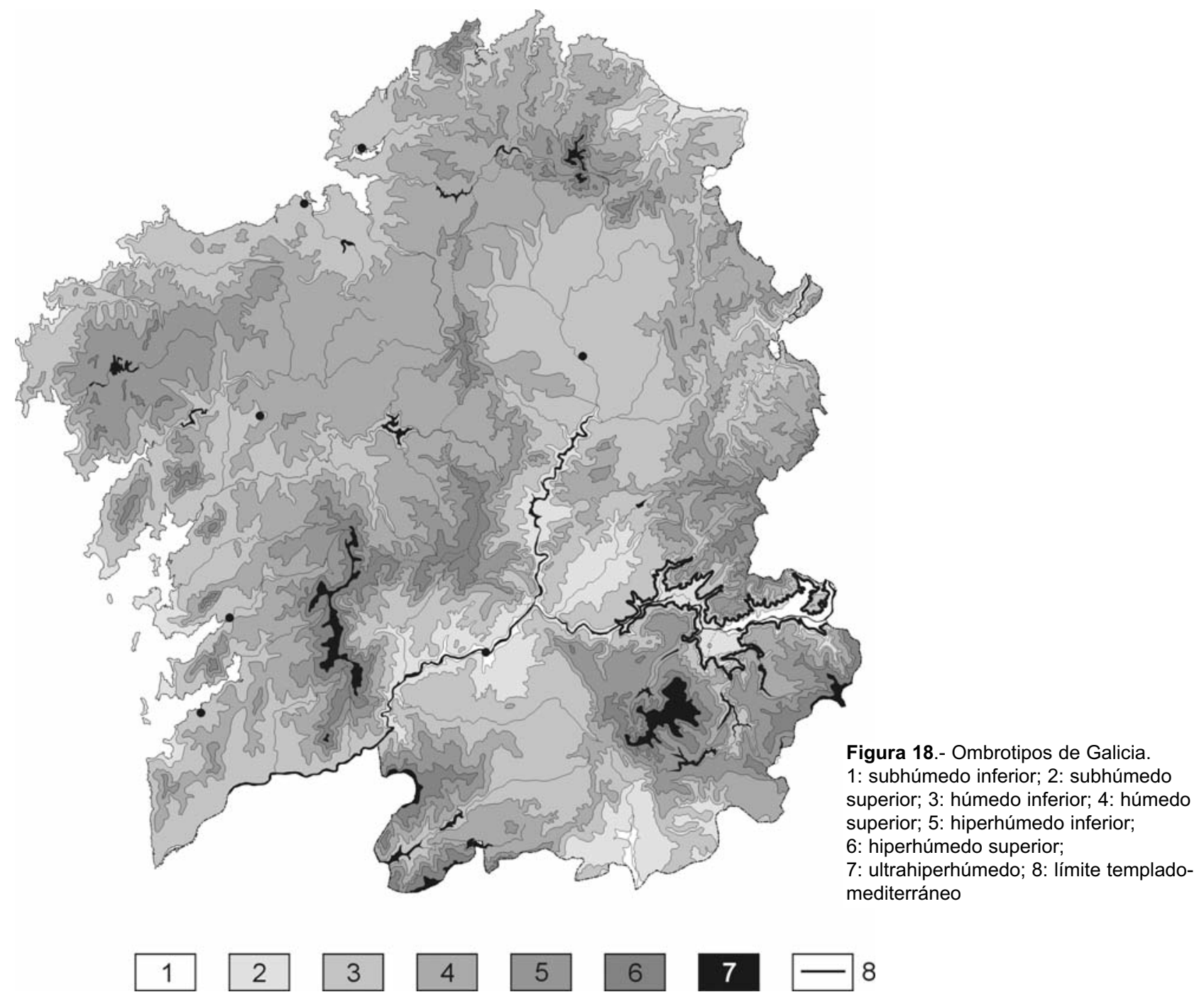

Figura 18.- Ombrotipos de Galicia. 1: subhúmedo inferior; 2 : subhúmedo : 6: hiperhúmedo superior; 7: ultrahiperhúmedo; 8: límite templadomediterráneo 
(Terra de Lemos) y gran parte de las comarcas de Verín y Riós.

El ombrotipo hiperhúmedo se extiende básicamente por las comarcas de Fisterra-Bergantiños en el NW de Galicia, así como por las partes altas de las sierras, tanto de la Dorsal como Septentrionales, Orientales y Meridionales. Por último, el ombrotipo ultrahiperhúmedo está representado exclusivamente en la Serra do Xistral, los sectores culminantes de las sierras fronterizas entre Pontevedra y Ourense y en las cumbres de las sierras de Leboreiro, Xurés, Queixa y Trevinca.

Dentro de los territorios mediterráneos las áreas bajas de Valdeorras reciben los valores mínimos de precipitación anual, lo que unido a su elevada termicidad, hace que presenten un ombrotermotipo subhúmedo inferior, mientras que el resto de comarcas se incluyen en el horizonte superior de este tipo ómbrico (Figura 18).

\section{Valoración de los resultados obtenidos y aplicabilidad}

A lo largo del proceso de elaboración de la cartografía bioclimática aquí presentada se han puesto de manifiesto diversas cuestiones que conviene tener en cuenta a la hora de interpretar los resultados obtenidos.

Por un lado, como en cualquier otro tipo de cartografía basada en cálculos derivados de datos tomados en una red de estaciones de muestreo, la fialibilidad de esta aproximación bioclimática es tanto mayor cuanto más densa sea la red de estaciones empleada. A este respecto, se sigue observando una importante carencia de estaciones en áreas para las que se presume la existencia de fuertes gradientes en los parámetros climáticos empleados (temperaturas y precipitaciones). Este es el caso de todas las áreas montañosas de Galicia y, en especial en los sectores situados por encima de los $500 \mathrm{~m}$ en las sierras que forman parte de la Dorsal y las Montañas Septentrionales, y de los 900 en las del cuadrante suroriental (Ancares, Cebreiro, Courel, Trevinca, Queixa) y límite con Portugual. (Leboreiro, Quinxo, Sta. Eufemia, Xurés, Larouco). A pesar de que, de manera general, las áreas bajas se encuentran mejor representadas climática y bioclimáticamente, algunas de ellas son claramente deficitarias en estaciones meteorológicas, como se constata a lo largo de la cuenca baja del Río Miño, A Limia, gran parte del Val de Lemos o la cuenca del Río Eo, entre otras.

En parte, la ausencia de estaciones o su reparto poco adecuado, impiden determinar con precisión algunos de los aspectos representados en los mapas elaborados, como puede ser el caso de los tipos termométricos u ómbricos con menor representación espacial en el territorio analizado o la pertenencia a un tipo u otro de macrobioclima en el caso de las áreas situadas en el contacto entre estos dos dominios climáticos. Estas situaciones se han resuelto en el presente trabajo teniendo en cuenta homologías climáticas o haciendo uso de gradientes cuya validez ha sido comprobada en áreas próximas para las que existe un registro climático fiable.
Una cuestión que se viene debatiendo desde hace unos años en diferentes foros y, que en el ámbito terrritorial de Galicia se plasma en la "Estratexia Galega contra o Cambio Climático", es la necesidad de contar con redes de toma de datos ambientales, entre las que se encuentran los climáticos, con la finalidad de monitorizar los cambios que en nuestro entorno puede provocar el calentamiento global. Desde esta perspectiva, los efectos del ascenso térmico podrían ser predecidos con un cierto grado de fiabilidad en las áreas bajas y más próximas al litoral, ya que en ellas se concentra una proporción elevada de las estaciones meteorológicas con datos disponibles. Sin embargo, las áreas montañosas, dentro de las que se concentra una parte fundamental de la potencialidad productiva (sistemas agrícolas y forestales) y de la biodiversidad del territorio gallego, aparecen nuevamente como claramente deficitarias, tanto en información pretérita como actual, desde el punto de vista bioclimático.

En el plano del mantenimiento de la diversidad biológica tienen especial relevancia los hábitats más marcadamente orófilos existentes en nuestro terrritorio, entre los que se encuentran diversos tipos de bosques caducifolios, grandes extensiones de matorrales, herbazales naturales y seminaturales, medios ligados a sustratos rocosos y turberas. Sería muy deseable, a estos efectos, implantar a la mayor brevedad posible una adecuada monitorización climática de estos ecosistemas con la ubicación de equipos de medición en los sectores de cumbres de las sierras orientales de Galicia (desde A Fonsagrada hasta las cumbres de Trevinca, pasando por la Serra dos Ancares, O Cebreiro y O Courel), la Serra do Xurés y la Serra do Xistral. Ello contribuiría, además, a un mejor conocimiento de las relaciones entre los parámetros climáticos y la distribución de los hábitats que caracterizan los medios de montaña en el extremo SW del continente europeo, así como incrementar la fiabilidad y grado de resolución de los modelos y diseños cartográficos.

\section{Bibliografía}

Alcalde Olivares, C., García-Amorena, I., Gómez Manzaneque, F., Maldonado Ruiz, J., Morla Juaristi, C., Postigo Mijarra, J.M., Rubiales Jiménez, J.M. \& Sánchez Hernando, L.J. (2004): Nuevos datos de carbones y maderas fósiles de Pinus pinaster Aiton en el Holoceno de la Península Ibérica. Invest Agrar: Sist. Recur. For. (2004) Fuera de serie, 152-163.

Amigo, J. (1984): Estudio de los matorrales y bosques de la Sierra del Caurel (Lugo). Tesis Doctoral inédita. 248 pp. Facultad de Farmacia. Universidade de Santiago.

Amigo, J. \& Romero, M.I. (1994): Vegetación atlántica bajo clima mediterráneo: un caso en el noroeste ibérico. Phytocoenologia, 22(4): 583-603.

Brunhes, J. (1902): L'Irrigation: ses conditions géographiques, ses modes et son organisation. Paris.

Daget, Ph. (1977): Le bioclimat méditerranéen: caractères généraux, modes de caracterisation. Vegetatio 34: 1-20. 
Dantín Cereceda, J. (1913): El concepto de región natural en geografía. Bol. Real Soc. Esp. Hist. Nat., vol. XIII: 50714

Dantín Cereceda, J. (1916): Dry-farming. Cultivo de las tierras de secano en las comarcas áridas de España. Gutemberg. 148 pp. Guadalajara.

Dantín Cereceda, J. (1922): Ensayo acerca de las regiones naturales de España. 386 pp. Museo Pedagógico Nacional. Madrid.

de Uña Álvarez (2001): El Clima. En: A. Precedo Ledo \& J. Sancho Comíns (Dir.): Atlas de Galicia. Tomo I: 137-155. Sociedade para o Desenvolvemento Comarcal de Galicia. Consellería da Presidencia. Xunta de Galicia. Santiago de Compostela.

Díaz-Fierros Viqueira, F. (1971): Contribución a la climatología agrícola de Galicia. Monografías de la Universidad de Santiago de Compostela, 8. 110 pp. Secretariado de Publicaciones. Universidade de Santiago de Compostela. Santiago de Compostela.

Díaz González, T.E. \& Fernández Prieto J.A. (1994): El paisaje vegetal de Asturias. Itinera Geobot. 8: 5-242.

Emberger, L. (1939): Aperçu général sur la végétation du Maroc. Veroff. Geobot. Inst. Rübel, 14: 40-157. Zurich.

Font Tullot, I. (2000): Climatología de España y Portugal. Nueva Edición. 422 pp. Ed. Universidad de Salamanca. Salamanca.

García Rio, R. \& Navarro Andrés, F. (1994): Flora y vegetación cormofíticas de las comarcas zamoranas del Pan, Tera y Carballeda. Stvdia Botanica, 12: 23-202.

Gaussen, H. (1954): Theorie et classification des climats et microclimats. Actes VII Cong. Int. Bot.: 125-130. Paris.

Giménez de Azcárate, J. (1993): Estudio fitosociológico de la vegetación de los afloramientos calizos de Galicia. Tesis Doctoral inéd. 310 pp. Facultade de Bioloxía. Universiade Santiago de Compostela.

Guitián Rivera, J. (1984): Estudio de la vegetación herbácea de la Sierra del Caurel (Lugo). - Tesis Doctoral inédita. 330 pp. Facultad de Farmacia. Universidad de Santiago de Compostela.

Izco, J. (1987): Galicia. En: M. Peinado Lorca \& S. RivasMartínez (Eds.): La Vegetación de España: 385-418. Col. Aula Abierta $n^{\circ} 3$. Servicio de Publicaciones. Universidad de Alcalá de Henares.

Izco, J. (1989): El Río Miño: barrera y camino en la migración de las plantas. Conferencias sobre el Rio Miño: 87-97. Caixa Ourense.

Izco, J. Amigo, J. \& Guitián, J. (1985): El papel de la topografía en la transición Eurosiberiano-Mediterranea en el extremo noroeste ibérico. Colloques Phytosociologiques, 13: $344-359$.

Lautensach, H. (1967): Geografía de España y Portugal. 60 pp. Ed. Vicens Vives. Barcelona.
López de Heredia, U., Carrión, J. S., Jiménez, P., Collada, C. \& Gil, L. (2007): Molecular and palaeoecological evidence for multiple glacial refugia for evergreen oaks on the Iberian Peninsula. J. Biogeogr. 34: 1505-1517.

Köppen, W. P. (1918): Klassification der Klimate nach Temperatur, Niederschlag und Jahreslauf. Petermanns Geog. Mitt. 64: 193-203.

Masachs Alavedra, V. (1954): Capitulo III: Tipos de climas regionales. En: Manuel de Terán (Dir.): Geografía de España y Portugal. Tomo II: 53-65. Montaner y Simón, S.A. Barcelona.

Fernandes Mesquita, S.C.P. (2005): Modelação Bioclimática de Portugal Continental. Dissertação para obtenção de Grau de Mestre em Sistemas de Informação Geográfica (Inédita). 129 pp. Instituto Superior Técnico. Universidade Técnica de Lisboa.

Ortiz, S. (1986): Series de vegetación y su zonación altitudinal en el macizo de Pena Trevinca y Serra do Eixo. Tesis Doctoral inédita. 509 pp. Departamento de Biología Vegetal. Universidad de Santiago de Compostela.

Ortiz, S. \& Rodríguez-Oubiña, J. (1993): Synopsis of the Rupicolous Vegetation of Galicia (North-western Iberian Peninsula). Folia Geob. Phytotax., 28: 15-49.

Ortiz, S.; Izco, J. \& Rodríguez-Oubiña, J. (1997): Complejos de vegetación del Macizo de Pena Trevinca y Serra do Eixo (NO de la Península Ibérica). Phytocoenologia, 27 (1): 2552.

Penas Merino, A., García González, M.E., Herrero Cembranos, L., Puente García, E. \& de Godos de Francisco, M. (1995): Pisos bioclimáticos: termotipos. En: A. García Cortés, E. Gallego Valcárce \& D. Berettino Fraile: Atlas de Medio Natural de la provincia de León: 21-22. ITGE-Diputación de León. Madrid.

Penas Merino, A., García González, M.E., Herrero Cembranos, L. \& Puente García, E. (1995): Pisos bioclimáticos: termotipos. En: A. García Cortés, E. Gallego Valcárce \& D. Berettino Fraile: Atlas de Medio Natural de la provincia de León: 23-24. ITGE-Diputación de León. Madrid.

Pérez Alberti, A. (1982): Climatoloxía. En: A. Pérez Alberti (Dir.): Xeografía de Galicia. Tomo I: O Medio: 71-96. Ed. Sálvora. Santiago de Compostela.

Pérez Alberti, A. (1983): A Xeografía. 274 pp. Ed. Galaxia. Vigo.

Pulgar, I. (1999): La vegetación de la Baixa Limia y Sierras del entorno. Tesis Doctoral inédita. Facultade de Farmacia. Universidade de Santiago de Compostela.

Ramil-Rego, P., Rodríguez-Guitián, M.A. \& Muñoz-Sobrino, C. (1998): Sclerophyllous vegetation dynamics in the north of the Iberian peninsula during the last 16.000 years. Global Ecology and Biogeography Letters 7: 335-351.

Rivas-Martínez, S. (1979): Brezales y jarales de Europa occidental (Revisión fitosociológica de las clases CallunoUlicetea y Cisto-Lavanduletea). Lazaroa 1: 5-119. 
Rivas-Martínez, S. (1983): Pisos bioclimáticos de España. Lazaroa 5: 33-43.

Rivas Martínez, S. (1987): Memoria del Mapa de Series de Vegetación de España. Serie Técnica n¹: 9-208. I.C.O.N.A. Madrid.

Rivas-Martínez, S. (1996): Bioclimatic Map of Europe. Discurso de investidura Dr. "Honoris causa". Universidad de Granada. Serv. Pub. Universidad de Granada.

Rivas-Martínez, S. (1997): Syntaxonomical synopsis of the potential natural plant communities of North America, I. Itinera Geobot. 10: 5-148.

Rivas-Martínez, S., Sánchez Mata, D. \& Costa, M. (1999): Syntaxonomical synopsis of the potential natural plant communities of North America, II. Itinera Geobot. 12: 5-316.

Rivas-Martínez, S. \& Loidi Arregui, J. (1999): Bioclimatology of the Iberian Peninsula. En: S. Rivas-Martínez, J. Loidi Arregui, M. Costa Taléns, T.E. Díaz González, \& A. Penas Merino: Iter ibericum A.D. MIM. Itinera Geobot. 13: 41-47.
Rivas-Martínez, S. (2007): Mapa de series, geoseries y geopermaseries de vegetación de España (Memoria del Mapa de Vegetación Potencial de España. Parte 1). Itinera Geobot. (Nueva Serie) 17. 436 pp.

Rodríguez-Oubiña, J. (1986): Estudio fitosociológico de las brañas de la provincia de A Coruña. Tesis Doctoral inédita. 355 pp. Facultad de Farmacia. Universidade de Santiago de Compostela.

Thornthwaite, C. W. (1931): The climates of North America according to a new classification. Geogr. Rev., 21, 633-655.

Tormo Molina, R., Ruiz Téllez, T. \& Devesa Alcaraz, J. A. (1992): Aportación a la bioclimatología de Portugal. Anales Jard. Bot. Madrid 49(2): 245-264.

Torres Luna, M.P., Lois González, R.C. \& Pérez Alberti, A. (1993): A Montaña galega. O home e o Medio. Biblioteca de Divulgación. Serie Galicia, 13. 221 pp. Serv. de Pub. e Int. Cient. Universidade de Santiago de Compostela.

\section{Anexo. Diagnosis bioclimática de las estaciones meteorológicas empleadas en este trabajo}

$\begin{array}{rll}\text { N}^{0} & \text { Prov. } & \text { Estación } \\ 1 & \text { C } & \text { A Capela C.F. } \\ 2 & \text { C } & \text { A Coruña } \\ 3 & \text { C } & \text { A Mourela } \\ 4 & \text { C } & \text { Aranga-A Reborica } \\ 5 & \text { C } & \text { Areosa } \\ 6 & \text { C } & \text { Bañobre } \\ 7 & \text { C } & \text { Barallobre } \\ 8 & \text { C } & \text { Betanzos } \\ 9 & \text { C } & \text { Boimorto } \\ 10 & \text { C } & \text { Boiro } \\ 11 & \text { C } & \text { Bugalleira } \\ 12 & \text { C } & \text { Cañas (Sta. Eulalia) } \\ 13 & \text { C } & \text { Capelada } \\ 14 & \text { C } & \text { Carballo } \\ 15 & \text { C } & \text { Castrelo (Vimianzo) } \\ 16 & \text { C } & \text { Cecebre } \\ 17 & \text { C } & \text { Corcubión } \\ 18 & \text { C } & \text { Coristanco-Fonteboa } \\ 19 & \text { C } & \text { Dodro-A Poza } \\ 20 & \text { C } & \text { Estaca de Bares } \\ 21 & \text { C } & \text { Eume-Central } \\ 22 & \text { C } & \text { Fene-Maniños } \\ 23 & \text { C } & \text { Fisterra (semáforo) } \\ 24 & \text { C } & \text { Gandario } \\ 25 & \text { C } & \text { Guisamo } \\ 26 & \text { C } & \text { Herbón (Padrón) } \\ 27 & \text { C } & \text { Irixoa-Outeiro de Mántaras } \\ 28 & \text { C } & \text { Labacolla (Aeroporto) } \\ 29 & \text { C } & \text { Louro } \\ 30 & \text { C } & \text { Mabegondo } \\ 31 & \text { C } & \text { Malpica } \\ 32 & \text { C } & \text { Marantes } \\ 33 & \text { C } & \text { Marco da Curra } \\ 34 & \text { C } & \text { Melide } \\ 35 & \text { C } & \text { Montaos } \\ 36 & \text { C } & \text { Monte Costa Grande (Muros) } \\ 37 & \text { C } & \text { Monte Iroite } \\ 38 & \text { C } & \text { Monte Pena de Rianxo } \\ 39 & \text { C } & \text { Montefaro } \\ 40 & \text { C } & \text { Monteventoso } \\ & & \end{array}$

Alt. $(\mathrm{m}): \mathrm{Pp} \quad \mathrm{Tp} \quad \mathrm{t} \quad \mathrm{M} \quad \mathrm{m}$ It $\mathrm{tc}$ tf Ic Itc lo lo2 lo3 lo4 Diagnosis bioclimática $3642341170514,212,34,731219,8 \quad 8,5 \quad 11,331213,734,825,326,22$ Tt Smhoc Tts Hhi $2010131674 \quad 14,012,8 \quad 7,0338 \quad 18,8 \quad 9,9 \quad 8,9338 \quad 6,05 \quad 1,952,362,91 \quad \mathrm{Tsm}$ Shoc Tts $\mathrm{Hi}$ $4501611138211,510,33,425316,8 \quad 6,7 \quad 10,125311,662,763,414,64 \quad \mathrm{Tt}$ Shoc Mti Hs $5001676142111,811,01,123918,2$ 6,1 12,1 239 11,79 2,67 3,12 4,34 Tt Smhoc Mts Hs $3431580143111,911,22,926017,6 \quad 6,9 \quad 10,726011,042,643,154,29$ Tt Shoc Mti Hs $601255168314,013,75,533219,6 \quad 9,3 \quad 10,33327,46 \quad 2,082,533,67 \quad \mathrm{Tt}$ Shoc Tts $\mathrm{Hi}$ $1001344156613,1 \quad 13,08,6347 \quad 18,1 \quad 8,6 \quad 9,5 \quad 347 \quad 8,58 \quad 3,043,583,91 \quad \mathrm{Tt}$ Shoc Tts $\mathrm{Hi}$ $38999147412,3 \quad 11,8 \quad 4,2283 \quad 16,9 \quad 8,0 \quad 8,9283 \quad 6,78 \quad 1,58 \quad 2,042,89$ Tsm Shoc Mti $\mathrm{Hi}$ $4801415138311,511,01,924417,4$ 6,3 11,1 244 10,23 2,02 2,65 4,15 Tt Smhoc Mti Hs $1082028178514,911,6 \quad 6,933421,1 \quad 9,3 \quad 11,833411,363,484,194,79$ Tt Smhoc Tts Hs $601328156813,111,6 \quad 5,1297 \quad 18,1 \quad 8,7 \quad 9,4297 \quad 8,47 \quad 2,783,414,20 \quad \mathrm{Tt}$ Shoc Tts $\mathrm{Hi}$ $1001126151512,613,12,027717,9 \quad 7,5 \quad 10,4277 \quad 6,48 \quad 2,232,453,14 \quad$ Tt Shoc Mti $\mathrm{Hi}$ $3982039138211,510,04,025516,5 \quad 7,0 \quad 9,525514,754,53 \quad 5,556,28$ Tt Shoc Mti Hhi

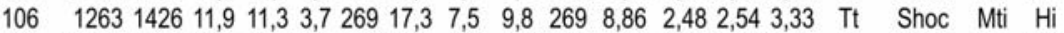
$2602305161713,514,43,6315 \quad 18,9 \quad 9,0 \quad 9,9 \quad 31514,253,574,005,91 \quad \mathrm{Tt}$ Shoc Tts Hhi $401094153712,814,12,028918,2$ 8,1 10,1 2897,12 1,81 2,26 3,08 Tsm Shoc Mti $\mathrm{Hi}$ $1201650194516,2 \quad 14,67,938720,8 \quad 11,2 \quad 9,6 \quad 387 \quad 8,48 \quad 2,902,503,14 \quad \mathrm{Tt}$ Shoc Tti $\mathrm{Hi}$ $1261414162613,6 \quad 13,44,4314 \quad 18,8 \quad 8,9 \quad 9,9314 \quad 8,69 \quad 1,87 \quad 2,36 \quad 3,42 \quad \mathrm{Tsm}$ Shoc Tts $\mathrm{Hi}$ $2603021161313,411,85,230419,3 \quad 8,510,830418,734,105,267,56$ Tt Shoc Tts Hhs $80 \quad 1063157013,1 \quad 12,56,1317 \quad 17,9 \quad 9,3 \quad 8,6 \quad 317 \quad 6,76 \quad 2,332,76 \quad 3,59 \quad \mathrm{Tt}$ Shoc Tts $\mathrm{Hi}$ $731911180815,113,06,834921,8 \quad 9,9 \quad 11,934910,572,893,174,34 \quad \mathrm{Tt}$ Smhoc Tts Hs $301274170714,213,05,232419,6 \quad 9,3 \quad 10,3324 \quad 7,47 \quad 1,932,293,04$ Tsm Shoc Tts $\mathrm{Hi}$ $100943172714,412,67,734719,110,1 \quad 9,0347 \quad 5,46 \quad 1,291,562,12$ Tsm Shoc Tts Shs $4 \quad 1118176514,7 \quad 14,15,734520,0 \quad 9,9 \quad 10,1345 \quad 6,33 \quad 1,732,152,95 \quad T s m$ Shoc Tts $\mathrm{Hi}$ $1501097168414,013,06,033019,4 \quad 9,5 \quad 9,93306,51 \quad 1,77 \quad 1,852,65 \mathrm{Tsm}$ Shoc Tts $\mathrm{Hi}$ $58 \quad 1595176514,713,44,732821,0 \quad 9,1 \quad 11,9328 \quad 9,04 \quad 1,992,513,41$ Tsm Smhoc Tts Hs $3981768147512,310,63,226118,3 \quad 6,8 \quad 11,526111,993,784,264,83$ Tt Smhoc Mti Hs $3161866145312,110,73,626417,7 \quad 7,1 \quad 10,626412,843,093,975,09$ Tt Shoc Mti Hhi 11014621871 15,6 14,7 7,0 $37320,910,910,03737,81$ 1,912,21 3,19 Tsm Shoc Tti $\mathrm{Hi}$ $100972156913,1 \quad 13,3 \quad 3,4298 \quad 18,4 \quad 8,3 \quad 10,1298 \quad 6,19 \quad 1,471,862,73 \quad \mathrm{Tsm}$ Shoc Tts $\mathrm{Hi}$ $40 \quad 1181168414,013,7 \quad 6,5342 \quad 18,5 \quad 10,1 \quad 8,4 \quad 342 \quad 7,01 \quad 1,852,253,05$ Tsm Shoc Tts $\mathrm{Hi}$ 30016221551 12,9 12,3 3,1 283 18,9 7,7 11,2 283 10,46 2,38 2,93 4,47 Tt Smhoc Mti Hs $6501468132911,1 \quad 8,4 \quad 3,122617,9 \quad 5,8 \quad 12,122611,042,553,114,45$ Tt Smhoc Mts Hs $4541591136611,4 \quad 10,41,423217,4 \quad 6 \quad 11,723211,652,362,934,39$ Tt Smhoc Mts Hs $306 \quad 1684148112,3 \quad 10,7 \quad 3,326318,3 \quad 7,1 \quad 11,226311,372,392,943,95$ Tt Smhoc Mti Hs $2301801151112,610,95,028516,98,0 \quad 8,928511,92 \quad 3,534,445,46$ Tt Shoc Mti Hs $6852164139711,6 \quad 9,2 \quad 3,824617,4 \quad 6,5 \quad 10,9246 \quad 15,492,993,915,92$ Tt Shoc Mti Hhi $1401921167814,012,75,131819,98,7 \quad 11,231811,452,463,154,03$ Tt Smhoc Tts Hs $2401180166313,912,37,333519,0 \quad 9,8 \quad 9,2 \quad 335 \quad 7,09 \quad 2,052,263,64 \quad \mathrm{Tt}$ Shoc Tts $\mathrm{Hi}$ $240999159313,311,46,9316 \quad 18,3 \quad 9,1 \quad 9,2 \quad 316 \quad 6,27 \quad 2,022,323,03 \quad \mathrm{Tt}$ Shoc Tts $\mathrm{Hi}$ 
№ Prov. Estación

41 C Negreira

42 C Noia

43 C O Barbanza

44 C O Burgo

45 C O Burgo (Univ. Laboral)

46 C Ordes

47 C Présaras

48 C Regos (Minas de San Finx)

49 C Rianxo

50 C Rio do Sol

51 C S. Andrés de Meirama

52 C Santiago de Compostela

53 C Serra de Outes

54 C Sobrado dos Monxes

55 C St ${ }^{2}$ Uxia de Ribeira

56 C Sta. Cruz-Viveiro

57 C Tambre (Emb.Barrié Maza)

58 C Teixeiro

59 C Trazo

60 C Vilarmaior-Armada

61 C Vimianzo

62 C Zas-Andragalla

63 C Zas-Muiños

64 LU A Conchada

65 LU A Fonsagrada

66 LU Alfoz-A Seara

67 LU As Rozas

68 LU Belesar (Embalse)

69 LU Benquerencia

70 LU Bóveda-Ver

71 LU Burela + Burela "Instituto"

72 LU Castro de Rei

73 LU E.C.A. Pedro Murias

74 LU Escairón-IBERDUERO

75 LU Estación Ancares

76 LU Ferreira (Pantón)

77 LU Fragavella

78 LU Fulgueira de Aigas

79 LU Granxa Barreiros

80 LU Guitiriz-Balneario

81 LU Lobeiras-Turb. Buyo y Gistral

82 LU Lugo

83 LU Mondoñedo

84 LU Monforte de Lemos

85 LU Monforte de Lemos - E. A.

86 LU Monte Ladairo (Guntin)

87 LU Monte Panda

88 LU Montefurado (Embalse)

89 LU OXipro

90 LU Os Peares (Embalse)

91 LU Outeiro de Rei

92 LU Pedrafita do Cebreiro

93 LU Penedo do Galo

94 LU Póboa de Brollón - A Veiga

95 LU Punto Centro

96 LU Santalla

97 LU Sequeiros (Embalse)

98 LU Sta. Cruz de Incio

99 LU Veiga de Brañas- Rubiais

100 LU Veneira de Roque

101 LU Viveiro (A Xunqueira)

102 OU A Rúa-Petin

103 OU A Veiga

104 OU Allariz

105 OU Alto do Rodicio

106 OU As Conchas (Embalse)

107 OU Bao (Embalse)

108 OU Barxa

109 OU Boimorto

110 OU Cabeza de Manzaneda

111 OU Calvos

112 OU Camba

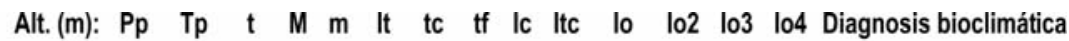

18321721494 12,5 11,0 2,6 261 18,5 6,8 11,7 261 14,54 3,65 4,12 4,45 Tt Smhoc Mti Hhi $1041442166313,912,14,130120,28,1 \quad 12,1301 \quad 8,67 \quad 2,742,993,97$ Tt Smhoc Tts Hi $6003372145012,111,13,426619,0 \quad 7,2 \quad 11,826623,264,534,906,38$ Tt Smhoc Mti Hhs $601103168614,1 \quad 12,75,432219,5 \quad 9,1 \quad 10,4322 \quad 6,54 \quad 1,902,252,62$ Tsm Shoc Tts Hi $101133159513,3 \quad 11,8 \quad 5,4305 \quad 18,2 \quad 8,9 \quad 9,3 \quad 305 \quad 7,10 \quad 2,192,602,85 \quad \mathrm{Tt}$ Shoc Tts $\mathrm{Hi}$ $2821786151812,7 \quad 11,52,6268$ 18,6 7,1 11,5 268 11,76 2,13 2,44 3,72 Tt Smhoc Mti Hs $4451561144512,011,72,025717,86,910,925710,802,663,274,34 \quad \mathrm{Tt}$ Shoc Mti Hs $2811507150312,510,93,3267$ 18,5 7,2 11,3 267 10,03 2,66 3,03 3,72 Tt Smhoc Mti Hs $51945176214,713,5 \quad 5,934120,6 \quad 9,5 \quad 11,134111,042,122,553,67$ Tt Smhoc Tts Hs $3401634131511,0 \quad 9,4 \quad 3,5239$ 16,1 6,5 9,6 239 12,42 3,12 3,41 5,00 Tt Shoc Mts Hhi $2001539155312,913,22,6287$ 18,7 7,9 10,8 287 9,91 2,15 2,76 3,94 Tt Shoc Mti Hs $2601288155513,011,34,729018,9 \quad 8,0 \quad 10,9290 \quad 8,28 \quad 1,962,58$ 3,69 Tsm Shoc Mti Hi 1020831773 14,8 13,8 5,4 340 20,8 9,6 11,2 34011,75 3,22 3,50 4,90 Tt Smhoc Tts Hs $5111389129010,8 \quad 8,7 \quad 1,8213 \quad 16,7 \quad 5,7 \quad 11,0213 \quad 10,772,093,04$ 3,83 Tt Smhoc Mts Hs $2512441751 \quad 14,613,45,8338$ 20,5 9,4 11,1 $338 \quad 7,10 \quad 1,58$ 1,98 2,65 Tsm Smhoc Tts Hi $60973169714,112,96,233218,9 \quad 9,6 \quad 9,3332 \quad 5,73 \quad 1,87$ 1,85 2,54 Tsm Shoc Tts Shs 2017931741 14,5 11,5 4,5 305 21,5 8,0 13,5 305 10,30 2,43 2,86 4,02 Tt Smhoc Tts Hs $4921632141411,810,02,0238$ 17,9 6,2 11,7 238 11,54 2,35 2,95 4,09 Tt Smhoc Mts Hs $4111613135511,310,0 \quad 3,5248 \quad 16,5 \quad 6,7 \quad 9,8248 \quad 11,902,322,954,44 \quad \mathrm{Tt}$ Shoc Mti Hs $2741528162913,612,25,5313 \quad 19,0 \quad 8,910,1313 \quad 9,38 \quad 2,813,484,46$ Tt Shoc Tts Hs 13817981531 12,8 11,2 4,6 285 18,0 8,3 9,7 $28511,74 \quad 3,804,055,34$ Tt Shoc Mti Hs $4681613135513,112,9 \quad 3,8298 \quad 18,4 \quad 8,4 \quad 10,0298 \quad 9,38 \quad 2,722,84 \quad 4,11 \quad$ Tt Shoc Tts Hs $3101608141411,810,22,624617,36,8 \quad 10,524611,372,252,653,92 \quad T$ Tt Shoc Mti Hs 6007391503 12,5 9,5 2,1 241 20,1 5,9 14,2 241 4,92 1,40 1,44 1,61 Mpl Euoc Mms Shs $952138711299,4 \quad 7,1 \quad-1,015516,3 \quad 3,2 \quad 13,115512,292,493,354,62 \quad$ Tt Smhoc Sti Hhi 809261577 13,1 13,5 3,2 298 18,5 8,4 10,1 $298 \quad 5,87$ 2,09 2,29 2,86 Tt Shoc Tts Shs $446857137111,410,0 \quad 1,7231$ 17,6 5,8 11,8 231 6,25 1,60 2,29 3,12 Tsm Smhoc Mts Hi

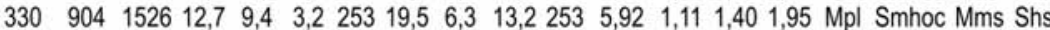
$251014165913,813,1 \quad 5,7326 \quad 19,2 \quad 9,4 \quad 9,8326 \quad 6,11 \quad 1,802,33$ 3,02 Tsm Shoc Tts Hi $\begin{array}{llllllllllllllll}361 & 896 & 1527 & 12,4 & 9,3 & 3,1 & 248 & 20,8 & 6,3 & 14,5 & 248 & 5,87 & 1,26 & 1,76 & 2,44 & \text { Tsm Euoc Mti Shs }\end{array}$ $20 / 80914174614,613,5 \quad 7,1352 \quad 19,7 \quad 10,3 \quad 9,43525,24 \quad 1,501,872,37$ Tsm Shoc Tti Shs $4391252140011,7 \quad 9,922,023517,7 \quad 6,1 \quad 11,6235 \quad 8,95 \quad 2,372,88$ 3,84 Tt Smhoc Mts Hi $43919169714,113,96,2343 \quad 19,310,19,2343 \quad 5,42 \quad 1,862,003,16$ Tsm Shoc Tts Shs $61111101318 \quad 11,0 \quad 8,6 \quad 1,020618,1 \quad 4,8 \quad 13,3206 \quad 8,42 \quad 1,44$ 2,00 2,84 Tsm Smhoc Mts Hi $1230139011669,7 \quad 7,2 \quad 0,5175 \quad 17,2 \quad 3,9 \quad 13,2175$ 11,92 3,14 4,00 5,32 Tt Smhoc Sti Hs

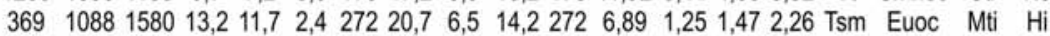

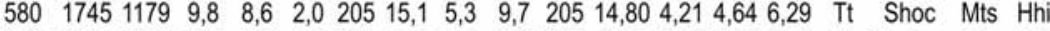
$91010641271 \quad 10,6 \quad 7,9 \quad 1,7202$ 17,8 4,9 12,9 202 8,37 2,40 2,78 4,10 Tt Smhoc Mts Hi 64014581298 10,8 8,6 0,6 200 17,7 4,6 13,1 20011,23 1,98 2,95 4,40 Tsm Smhoc Mts Hs 41013891339 11,2 9,1 1,3 215 18,1 5,2 12,9 215 10,38 1,95 2,45 3,62 Tsm Smhoc Mts Hs

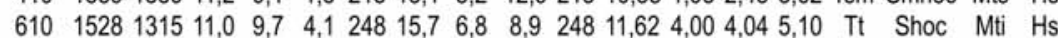
45410481428 11,9 9,3 2,4 236 18,6 5,8 12,8 236 7,34 1,76 2,19 3,05 Tsm Smhoc Mts $\mathrm{Hi}$ $1391101150012,511,8 \quad 4,328618,1 \quad 8,0 \quad 10,1286 \quad 7,34 \quad 1,912,33$ 3,32 Tsm Shoc Mti $\mathrm{Hi}$ 3008221671 13,9 11,2 2,4 275 21,8 6,8 15,0 275 4,92 0,82 1,19 1,98 Mpl Euoc Mms Shs

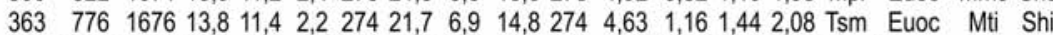

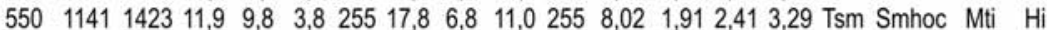

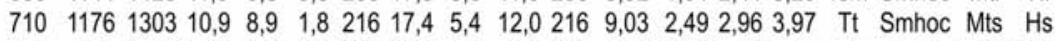
$270792158413,2 \quad 9,0 \quad 0,622822,6 \quad 4,8 \quad 17,8228 \quad 5,00 \quad 0,821,121,47 \quad M p l \quad S c o \quad M m s$ Shs $8401179121910,1 \quad 8,5 \quad 1,420016,8 \quad 4,9 \quad 11,9200 \quad 9,67 \quad 2,74$ 3,10 4,41 Tt Smhoc Mts Hs

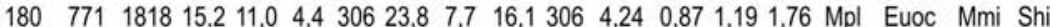
$4161050136511,4 \quad 9,6 \quad 2,4234 \quad 17,4 \quad 6,0 \quad 11,4234 \quad 7,69$ 2,12 2,24 2,41 Tt Smhoc Mts $\mathrm{Hi}$ $1104194410098,4 \quad 3,5 \quad 1,413315,8 \quad 2,4 \quad 13,4133 \quad 19,27 \quad 3,234,546,05 \quad$ Tt Smhoc Sti Hhs $3401210153812,811,3 \quad 6,5306 \quad 17,98,9 \quad 9,0306 \quad 7,87 \quad 3,003,274,04 \quad \mathrm{Tt}$ Shoc Tts $\mathrm{Hi}$ $4001070157012,910,51,925321,0 \quad 6,2 \quad 14,8253 \quad 6,82 \quad 1,59$ 2,06 2,97 Tsm Euoc Mti Hi $4261137132911,1 \quad 9,8 \quad 1,7226 \quad 17,4 \quad 5,7 \quad 11,7226 \quad 8,56 \quad 1,902,48$ 3,75 Tsm Smhoc Mts $\mathrm{Hi}$ $72013551250 \quad 9,8 \quad 9,2 \quad-0,5185$ 17,8 4,4 13,4 185 10,84 2,51 3,21 4,02 Tt Smhoc Sti Hs

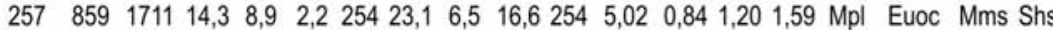
$73913791154 \quad 9,6 \quad 7,7 \quad-0,2171 \quad 16,5 \quad 3,7 \quad 12,4171 \quad 11,952,653,38$ 4,65 Tt Smhoc Sti Hs

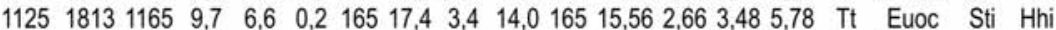
$9801719913 \quad 7,6 \quad 5,7 \quad-1,2121$ 13,9 $1,8 \quad 12,112118,834,075,037,09$ Tt Smhoc Sti Hhs

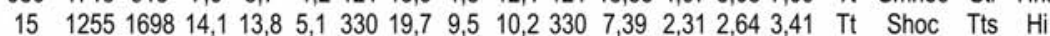
$298762186915,611,8$ 5,3 327 23,8 8,5 15,3 327 4,08 0,79 0,98 1,38 Mpl Euoc Mmi Shi $\begin{array}{lllllllllllllllll}868 & 965 & 1290 & 10,8 & 7,6 & -0,6 & 178 & 19,1 & 3,5 & 15,6 & 178 & 7,48 & 1,46 & 1,91 & 2,80 & \text { Tsm Euoc Sti } \mathrm{Hi}\end{array}$

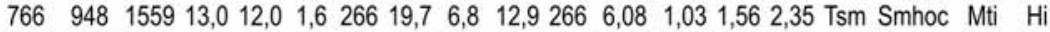
70017841187 9,9 8,9 $-0,7181$ 16,8 4,3 12,5 181 15,03 2,67 3,56 5,42 Tt Smhoc Sti Hhi

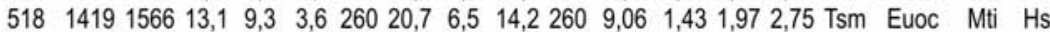

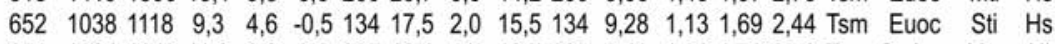
$6541094134911,2 \quad 9,0 \quad 0,320518,4 \quad 4,7 \quad 13,7205$ 8,11 1,26 1,79 2,59 Tsm Smhoc Mts Hi $4821117148912,410,8 \quad 1,825019,95,914,0250 \quad 7,50 \quad 1,291,782,86$ Tsm Euoc Mti $\mathrm{Hi}$

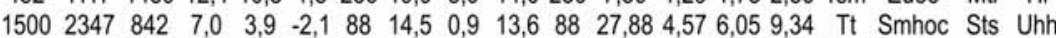
$908118011489,6 \quad 9,4-1,0180$ 16,3 4,2 12,1 180 10,28 1,52 2,10 3,00 Tsm Smhoc Sti Hs $1117203810028,4 \quad 5,8 \quad-2,1121 \quad 16,5 \quad 1,9 \quad 14,612120,34$ 2,60 3,96 5,99 Tt Euoc Sti Hhs 


\section{$N^{\circ}$ Prov. Estación}

113 OU Campobecerros

114 OU Castelo da Pena

115 OU Castiñeira

116 OU Castro Caldelas

117 OU Cenza

118 OU Chandrexa de Queixa (Embalse)

119 OU Esgos

120 OU Freás de Eiras

121 OU Guistolas (Embalse)

122 OU Lamalonga

123 OU Maceda

124 OU Manzaneda

125 OU Mesiego

126 OU Mesón de Pentes (A Gudiña)

127 OU O Barco de Valdeorras

128 OU Ourense

129 OU Parafita de Queixa

130 OU Pedreiriño

131 OU Pedrouzos (Castro Caldelas)

132 OU Portocamba

133 OU Povoa de Trives

134 OU Pumares

135 OU San Estevo (Embalse)

136 OU San Miguel de Vidueira (Manzaneda)

137 OU San Sebastián (Embalse)

138 OU San Vicente de Leira

139 OU Santa Eulalia (Embalse)

140 OU Seoane de Carballiño

141 OU Serra do Eixo

142 OU Sobradelo

143 OU Velle (Embalse)

144 OU Vila do Rei

145 OU Vilariño de Conso

146 OU Xinzo de Limia

147 OU Xunqueira de Espadanedo

148 PO A Cañiza

149 PO A Estrada

150 PO A Guardia

151 PO Arcos da Condesa

152 PO Cangas

153 PO Castriño (Campo Lameiro)

154 PO Castro Vicaludo

155 PO Corón-Vilanova de Arousa

156 PO Cuntis-Estacas

157 PO Fornelos de Montes-Estacas

158 PO Frieira (Embalse)

159 PO Granxa do Louro (O Porriño)

160 PO Illas Cies

161 PO Lalin

162 PO Lourizán

163 PO Mos

164 PO O Rosal (Novas)

165 PO Páramos de Guillarei

166 PO Peinador (Aeroporto)

167 PO Ponteareas

168 PO Pontevedra

169 PO Portodemouros (Embalse)

170 PO Ribadumia-Freixo

171 PO Salcedo (Misión Biolóxica)

172 PO Sanxenxo

173 PO Tui (Monte Aloia)

174 PO Vigo

175 PO Vilagarcia de Arousa

176 PO Vilariño-Cambados

177 PO Xende (A Lama)

178 PO Zamar de Rubiáns

179 AS Brañavara

180 AS Castropol

181 AS Figueras de Castropol

182 AS Grandas de Salime

183 AS La Caridad de El Franco-G.C.

184 AS Lorido
Alt. (m): Pp Tp $t \quad M \quad m$ It tc tf Ic Itc $10 \quad 102 \quad 103 \quad 104$ Diagnosis bioclimática

$98718111097 \quad 9,1 \quad 6,8 \quad-0,915017,4 \quad 2,6 \quad 14,815016,512,34$ 3,62 5,21 Tt Euoc Sti Hhi $740747140611,7 \quad 8,3 \quad 1,4214$ 19,5 5,2 14,2 $214 \quad 5,31$ 0,94 1,31 2,05 Tsm Euoc Mts Shs

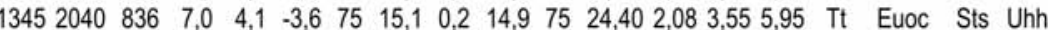
79311291333 11,1 8,6 0,4 201 18,7 4,6 14,1 2018,47 1,84 2,41 3,36 Tsm Euoc Mts $\mathrm{Hi}$ $\begin{array}{lllllllllllllllll}1500 & 1900 & 727 & 6,1 & 3,0 & -4,2 & 49 & 14,6 & -0,4 & 15,0 & 49 & 26,13 & 2,64 & 3,77 & 6,12 & \text { Tt } & \text { Euoc Oti Uhh }\end{array}$ 91011801228 10,2 7,4 0,4 180 18,0 3,9 14,1 180 9,61 1,32 1,85 3,28 Tsm Euoc Sti Hs $580895151412,610,93,026520,07,013,02655,91$ 0,96 1,26 2,24 Tsm Smhoc Mti Shs 30010081618 13,5 11,6 2,2 273 21,1 6,9 14,2 273 6,23 1,00 1,18 1,74 Mpl Euoc Mms Hi

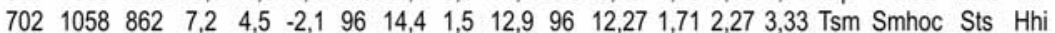
80011331245 10,4 9,6 $-0,3197$ 17,3 4,7 12,6 197 9,10 2,19 2,86 3,99 Tt Smhoc Mts Hs 60011321579 13,2 10,4 2,2 $25820,96,3 \quad 14,6258 \quad 7,17 \quad 2,03 \quad 1,892,88$ Tt Euoc Mti $\mathrm{Hi}$ $6571005134111,2 \quad 9,3 \quad 0,520919,7 \quad 4,0 \quad 15,72097,49$ 1,63 2,07 2,61 Tsm Euoc Mts $\mathrm{Hi}$ 40011181476 12,3 10,9 1,2 244 19,5 6,1 13,4 244 7,57 1,31 1,67 2,44 Tsm Smhoc Mti Hi $9001460128410,78,2 \quad 0,4193 \quad 18,6 \quad 4,3 \quad 14,3193$ 11,37 1,42 2,38 3,32 Tsm Euoc Mts Hs 3268021835 15,3 12,3 2,6 302 23,9 7,5 16,4 302 4,37 1,00 1,41 1,87 Mpl Euoc Mmi Shi $139773168414,010,33,728021,7 \quad 7,014,72804,590,68$ 1,08 1,56 Mpl Euoc Mms Shi $119412711090 \quad 9,1 \quad 6,9 \quad-0,7153$ 16,2 3,1 13,1 153 11,66 1,91 2,62 4,29 Tsm Smhoc Sti Hs

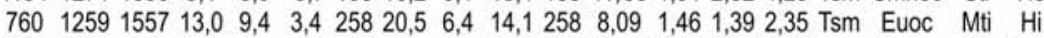

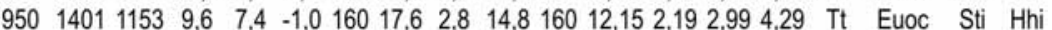
$954163411199,3 \quad 7,0 \quad-1,0153 \quad 17,6 \quad 2,7 \quad 14,9153 \quad 14,601,872,68$ 4,22 Tsm Euoc Sti Hhi $\begin{array}{llllllllllllllllll}780 & 875 & 1070 & 8,9 & 7,2 & -1,9 & 142 & 16,7 & 2,7 & 14,0 & 142 & 8,18 & 1,25 & 1,81 & 2,50 & \mathrm{Tsm} & \text { Euoc } & \mathrm{Sti} \\ \mathrm{Hi}\end{array}$

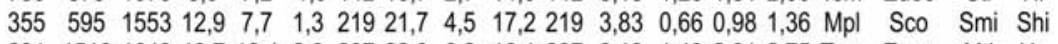
$2311516164913,712,42,628722,3 \quad 6,2 \quad 16,1287 \quad 9,19$ 1,43 2,01 2,75 Tsm Euoc Mti Hs 8709351281 10,7 9,6 0,2 205 17,5 4,9 12,6 205 7,30 1,26 1,87 2,89 Tsm Smhoc Mts $\mathrm{Hi}$

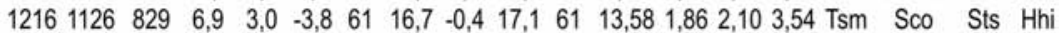
$64813731343 \quad 11,2 \quad 9,3 \quad 0,7212$ 19,5 4,2 15,3 212 10,22 1,70 2,28 3,34 Tsm Euoc Mts $H$

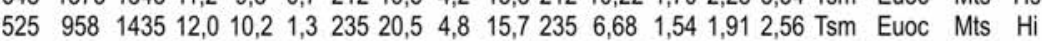
$4401424133711,1 \quad 9,6 \quad 0,5212$ 18,2 5,2 13,0 212 10,65 1,78 2,43 3,84 Tsm Smhoc Mts Hs $129010431085 \quad 9,0 \quad 5,6 \quad-0,9137 \quad 17,2 \quad 2,4 \quad 14,8137$ 9,61 2,68 2,34 3,39 Tt Euoc Sti Hs

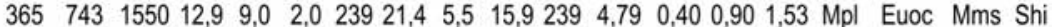
$108791 \quad 178014,811,93,730422,6 \quad 7,8 \quad 14,8304 \quad 4,44$ 1,31 1,49 2,07 Tsm Euoc Tts Shi $65711381348 \quad 11,2 \quad 9,3 \quad 1,0216 \quad 18,6 \quad 4,9 \quad 13,7216 \quad 8,44 \quad 1,16 \quad 1,68$ 2,40 Tsm Smhoc Mts Hi $758137110068,4 \quad 6,7 \quad-1,3138$ 16,6 2,7 13,9 138 13,63 1,77 2,55 3,75 Tsm Smhoc Sti Hhi

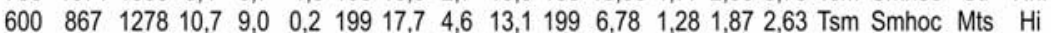

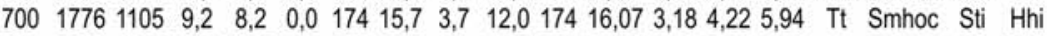
$5702377141911,810,03,225117,8 \quad 6,1 \quad 11,725116,753,403,594,88$ Tt Smhoc Mti Hhi 29618271588 13,2 11,8 $4,429419,07,911,129411,512,63$ 3,19 4,76 Tt Smhoc Tts Hs

$51314171814,313,15,933319,69,510,1333 \quad 7,650,951,522,69$ Tsm Shoc Tts Hi 21514571708 14,2 12,9 5,6 32720,7 9,3 $11,5327 \quad 8,53 \quad 1,87$ 2,29 3,31 Tsm Smhoc Tts Hi $301245183815,314,76,536520,510,6 \quad 9,93656,78 \quad 1,98$ 1,92 2,78 Tsm Shoc Tti $\mathrm{Hi}$ $41020021412 \quad 11,8 \quad 9,9 \quad 4,125817,4 \quad 7,0 \quad 10,425814,182,87 \quad 3,624,93 \quad \mathrm{Tt}$ Shoc Mti Hhi 45015451509 12,6 10,2 4,8 275 18,3 7,5 10,8 275 10,24 1,14 2,58 3,87 Tsm Shoc Mti Hs $201674179515,014,35,935220,210,110,13529,332,702,923,97$ Tt Shoc Tti Hs 31819091606 13,4 11,7 5,0 300 19,2 8,3 10,8 30011,88 2,59 3,46 4,69 Tt Shoc Tts Hs $75931171338 \quad 11,2 \quad 9,1 \quad 3,2234 \quad 17,6 \quad 6,2 \quad 11,4234 \quad 23,30 \quad 3,875,56 \quad 7,97$ Tt Smhoc Mts Hhs $651124183515,311,86,233322,5 \quad 9,0 \quad 13,53336,13 \quad 1,442,012,69$ Tsm Smhoc Tts Hi $291715168514,011,7 \quad 3,6293 \quad 19,9$ 7,6 12,3293 10,18 1,53 1,98 3,83 Tsm Smhoc Tts Hs $1708791663 \quad 13,9 \quad 9,9 \quad 4,7284$ 19,8 8,5 11,3 284 5,29 0,87 1,05 1,57 Mpl Smhoc Mms Shs

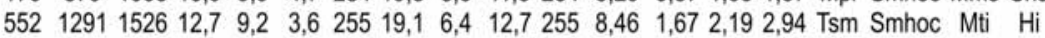
$601801170114,213,55,132819,4 \quad 9,3 \quad 10,1328$ 10,59 2,07 2,44 3,48 Tt Shoc Tts Hs 10019241703 14,2 12,9 5,4 325 20,1 8,9 11,2 325 11,30 2,49 2,79 3,52 Tt Smhoc Tts Hs $501573179915,013,7 \quad 5,233921,19,511,63398,75 \quad 1,351,642,93$ Tsm Smhoc Tts $\mathrm{Hi}$ $451478172614,4 \quad 12,03,129523,0 \quad 7,5 \quad 15,5295 \quad 8,56 \quad 1,972,37$ 3,30 Tsm Euoc Tts Hi $25819021584 \quad 13,2 \quad 11,1 \quad 4,929218,4 \quad 8,0 \quad 10,4292 \quad 12,012,423,034,63 \quad$ Tt Shoc Tts Hhi $1001485175814,713,13,931721,58,513,03178,451,661,993,14$ Tsm Smhoc Tts Hi $191600182215,213,36,735221,010,011,03528,78$ 1,87 2,29 3,52 Tsm Smhoc Tti Hi

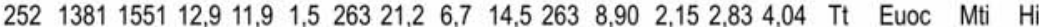
$651525180815,113,95,434421,1 \quad 9,7 \quad 11,4344 \quad 8,43 \quad 2,07$ 1,92 3,07 Tt Smhoc Tts $\mathrm{Hi}$ $401585172614,413,15,432919,6 \quad 9,2 \quad 10,4329 \quad 9,18 \quad 2,062,553,60$ Tt Shoc Tts Hs 1512261752 14,6 14,1 6,6 353 19,5 10,4 9,1 353 7,00 1,53 1,55 2,41 Tsm Shoc Tti Hi $4001930167414,011,4 \quad 3,629020,2 \quad 7,5 \quad 12,729011,53$ 2,65 3,42 4,55 Tt Smhoc Mti Hs $271414179014,913,56,935320,010,2 \quad 9,83537,90 \quad 1,512,003,14$ Tsm Shoc Tti $\mathrm{Hi}$ $361456184115,313,76,635621,5$ 10,1 $11,4356 \quad 7,91$ 1,71 2,05 3,44 Tsm Smhoc Tti $\mathrm{Hi}$ $6015351883 \quad 15,7 \quad 14,16,3 \quad 36122,1 \quad 10,311,8361 \quad 8,15 \quad 1,612,02 \quad 3,04$ Tsm Smhoc Tti Hi $48719471436 \quad 12,0 \quad 9,6 \quad 3,8254 \quad 17,9 \quad 6,7 \quad 11,2254$ 13,56 3,34 4,21 5,68 Tt Smhoc Mti Hhi $1001827170714,213,05,432620,19,011,132610,702,452,323,19$ Tt Smhoc Tts Hs 76017491196 10,0 8,0 2,3 203 15,5 5,1 10,4 203 14,63 5,00 5,26 7,85 Tt Shoc Mts Hhi $25998163513,611,8 \quad 5,931319,1 \quad 8,910,2313 \quad 6,10 \quad 2,322,593,34 \quad \mathrm{Tt}$ Shoc Tts $\mathrm{Hi}$ $20971 \quad 1623 \quad 13,513,4 \quad 5,132018,8 \quad 9,1 \quad 9,7320 \quad 5,98$ 2,29 2,57 3,26 Tt Shoc Tts Shs $\begin{array}{llllllllllllllll}640 & 1210 & 1363 & 11,4 & 9,6 & 1,4 & 224 & 18,2 & 5,5 & 12,7 & 224 & 8,88 & 2,31 & 2,77 & 3,85 & \text { Tt Smhoc Mts } \mathrm{Hi}\end{array}$ 6311071577 13,1 13,4 4,8 313 18,2 9,1 9,1 313 7,02 2,92 3,21 3,89 Tt Shoc Tts Hi $3401289145012,111,92,126118,0 \quad 7,0 \quad 11,0261 \quad 8,89 \quad 3,213,594,59$ Tt Smhoc Mti Hi 


\section{No Prov. Estación}

185 AS Luiña-Tormaleo

186 AS San Antolin de Ibias

187 AS San Martin de Oscos

188 AS Tapia de Casariego

189 LE Ponferrada

190 LE Puente de Domingo Flórez

191 LE Sobrado

192 LE Trabadelo

193 LE Villafranca del Bierzo

194 ZA Castromil

195 ZA Laguna Cárdena (embalse)

196 ZA Paramio de Sanabria

197 ZA Pias

198 ZA Porto

199 ZA Puebla de Sanabria-lberduero

200 ZA Requejo

201 PORT Ancora

202 PORT Beleiral

203 PORT Bragança

204 PORT Chaves

205 PORT Melgaço

206 PORT Monçao-Valinha

207 PORT Montalegre

208 PORT Senhora da Peneda

209 PORT Viana do Castelo

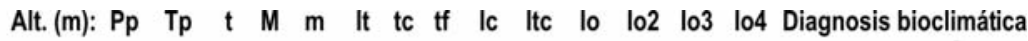

70018371268 10,6 9,3 -0,2 19717,4 4,6 12,8 197 14,49 3,74 4,47 5,96 Tt Smhoc Mts Hhi $3081243157613,111,2 \quad 1,726020,96,514,4260 \quad 7,89$ 1,89 2,26 3,31 Tsm Euoc Mti $\mathrm{Hi}$ $69714491182 \quad 9,9 \quad 8,4 \quad-0,2181$ 15,8 4,1 11,7 181 12,26 2,72 3,61 4,67 Tt Smhoc Sti Hhi $\begin{array}{llllllllllllllll}18 & 785 & 1554 & 13,0 & 12,1 & 6,2 & 313 & 17,7 & 9,1 & 8,6 & 313 & 5,05 & 1,99 & 2,73 & 3,03 & \text { Tsm Shoc Tts Shs }\end{array}$

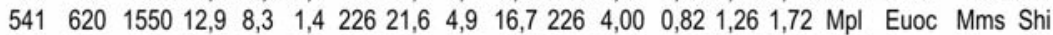

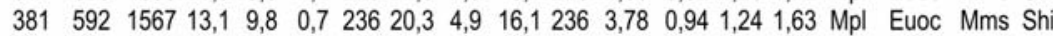

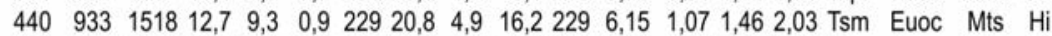

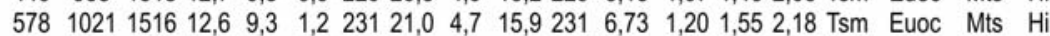

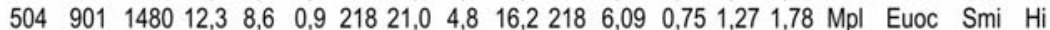
$104014131119 \quad 9,3 \quad 6,8 \quad-2,3138 \quad 18,1 \quad 2,2 \quad 15,9138$ 12,63 1,46 2,13 3,64 Tsm Euoc Sti Hhi $16001682770 \quad 6,4 \quad 3,3 \quad-4,948 \quad 15,3 \quad-0,9$ 16,2 48 21,84 1,45 2,33 4,57 Tsm Euoc Oti Hhs $10209011179 \quad 9,8 \quad 7,4 \quad-2,2150$ 18,1 2,6 15,5150 7,64 1,15 1,69 2,65 Tsm Euoc Sti $\mathrm{Hi}$ $\begin{array}{llllllllllllllllll}980 & 1482 & 958 & 8,0 & 4,6 & -4,1 & 85 & 17,3 & 0,2 & 17,1 & 85 & 15,47 & 0,82 & 2,03 & 3,95 & \text { Tsm } & \text { Sco Sts Hhi }\end{array}$ $14901430921 \quad 7,7 \quad 3,2 \quad-3,574 \quad 18,2 \quad-0,1 \quad 18,3 \quad 75 \quad 15,53$ 1,66 2,61 4,29 Tsm Sco Sts Hhi $\begin{array}{llllllllllllllll}960 & 966 & 1171 & 9,8 & 7,2 & -2,1 & 149 & 18 & 2,6 & 15,4 & 149 & 8,25 & 1,10 & 1,50 & 2,41 & \text { Tsm Euoc Sti } \mathrm{Hi}\end{array}$ $1006148411809,8 \quad 7,5 \quad-2,3150$ 18,3 2,5 15,8 150 12,58 1,36 2,10 3,48 Tsm Euoc Sti Hhi $131204168414,013,76,534217,910,17,8 \quad 340 \quad 7,15 \quad 1,922,052,68$ Tsm Hoc Tts $\mathrm{Hi}$ $5502583151612,610,23,626419,6$ 6,9 $12,726417,042,553,11$ 4,84 Tt Smhoc Mti Hhi $691721148612,47,9 \quad 1,121421,4 \quad 4,5$ 16,9 $214 \quad 4,850,570,901,35 \mathrm{Mpl}$ Euoc Smi Shs

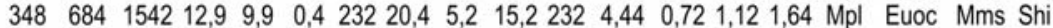
23512321710 14,3 11,1 3,6 290 21,5 7,3 14,2 290 7,20 1,08 1,60 2,47 Tsm Euoc Mti $\mathrm{Hi}$ $801220175914,712,34,531521,7 \quad 8,413,3315$ 6,94 1,38 1,41 2,44 Tsm Smhoc Tts $\mathrm{Hi}$ $1005136710879,1 \quad 6,3 \quad 0,4158$ 16,0 3,4 12,6 158 12,58 1,07 1,88 2,67 Tsm Smhoc Sti Hhi $6602826143011,9 \quad 8,3 \quad 4,324518,7 \quad 6,8 \quad 11,924519,762,13 \quad 3,07 \quad 6,21$ Tt Smhoc Mti Hhs $111471172514,413,16,8343 \quad 18,5$ 10,0 8,5 $343 \quad 8,53 \quad 2,942,503,67 \quad$ Tt Shoc Tts $\mathrm{Hi}$

Abreviaturas: Macroclimas: Tt: templado típico; Tsm: templado submediterráneo; Mpl: mediterráneo pluviestacional; Bioclimas: Hoc: euhiperoceánico; Shoc: subhiperoceánico; Smhoc: semihiperoceánico; Euoc: euoceánico; Sco: semicontinental; Termotiopos: Tti: termotemplado inferior; Tts: termotemplado superior: Mti: mesotemplado inferior; Mts: mesotemplado superior; Sti: supratemplado inferior; Sts: supratemplado superior; Oti: orotemplado inferior; Ombrotipos: Shs: subhúmedo superior; Hi: húmedo inferior; Hs: húmedo superior; Hhi: hiperhúmedo inferior; Hhs: hiperhúmedo superior; Uhh: ultrahiperhúmedo 